\title{
DIDÁCTICAS PARA LA FORMACIÓN EN INVESTIGACIÓN CONTABLE: UNA DISCUSIÓN CRÍTICA DE LAS PRÁCTICAS DE ENSEÑANZA*
}

\author{
SANDRA MILENA MUÑOZ LÓPEZ ${ }^{* * *}$, GUSTAVO ALBERTO RUIZ ROJAS**** \& HÉCTOR JOSÉ SARMIENTO RAMÍREZ***** \\ UNIVERSIDAD AUTÓNOMA LATINOAMERICANA \\ POLITÉCNICO COLOMBIANO JAIME ISAZA CADAVID
}

Recibido/ Received/ Recebido: 17/12/2013 - Aceptado/ Accepted / Aprovado: 26/08/2014

\begin{abstract}
Resumen
El presente artículo indaga sobre la forma en que se enseña la investigación en los programas de Contaduría Pública de Medellín. El método seguido en el estudio corresponde a un diseño combinado entre explicativo e interpretativo, que acudió a las fuentes primarias al consultar la experiencia de los profesores. Los resultados se dividen en tres grandes apartados: el primero expone la forma en que la investigación aparece en el currículo, el segundo analiza las experiencias aportadas por los profesores y el tercero discute el sentido que se halla en tales experiencias.

Palabras clave: Didáctica de la investigación, Investigación contable, Educación contable, Enseñanza de la investigación contable.
\end{abstract}

\section{DIDACTICS FOR THE FORMATION IN ACCOUNTING RESEARCH: A CRITICAL DISCUSSION OF TEACHING PRACTICES}

\begin{abstract}
The present article inquires about the ways that we teach research in the programs of Public Accounting in Medellin. The study used a mix method (explanatory and interpretive) taking as primary sources teachers' experiences. The results are divided in three sections: The first one exposes the ways in that research appears in the curriculum, the second one analyzed data provided by the teachers' experiences and the third one discusses the meaning that we found on such experiences.
\end{abstract}

Keywords: Didactics of the research, Accounting research, Accounting education, Teaching of accounting research.

Artículo de investigación derivado del proyecto "Didácticas para la formación en investigación contable en programas de Contaduría Pública en la ciudad de Medellín" (Código: 7-000022), realizado entre julio de 2012 y septiembre de 2013. Financiado por la Universidad Autónoma Latinoamericana y el Politécnico Colombiano Jaime Isaza Cadavid, Medellín (Colombia). En este trabajo fueron muy valiosos los aportes de Margarita Rodríguez y Lady Vanessa Restrepo, estudiantes de la Facultad de Contaduría Pública de la Universidad Autónoma Latinoamericana.

** Profesora Facultad de Contaduría Pública, Universidad Autónoma Latinoamericana, Medellín (Colombia). Correo electrónico: sandra.munozlo@unaula.edu.co. Tel: (57) (4) 5112199 Ext. 203. Dirección postal: Cra. 55A \# 49-51, Medellín.

*** Profesor Facultad de Contaduría Pública, Universidad Autónoma Latinoamericana, Medellín (Colombia). Correo electrónico: gustavo.ruiz@unaula.edu.co.

***** Profesor Facultad de Administración, Politécnico Colombiano Jaime Isaza Cadavid, Medellín (Colombia). Correo electrónico: teuken-bidikay@elpoli.edu.co. Tel: (57) (4) 3197900 / 444 7654. Dirección postal: Cra. 48 \# 7-151, Medellín. 


\title{
DIDÁTICAS PARA A FORMAÇÃO EM PESQUISA CONTÁBIL: UMA DISCUSSÃO CRÍTICA DAS PRÁTICAS DE ENSINO
}

\begin{abstract}
Resumo
O presente artigo indaga sobre a forma em que se ensina a pesquisa nos programas de Contabilidade Pública de Medellín. O método seguido no estudo corresponde a um desenho combinado entre explicativo e interpretativo, que foi às fontes primárias ao consultar a experiência dos professores. Os resultados se dividem em três grandes partes: a primeira expõe a forma em que a pesquisa aparece no currículo, a segunda analisa as experiências dos professores e a terceira discute o sentido encontrado em tais experiências.
\end{abstract}

Palavras chave: Didática da pesquisa, Pesquisa contábil, Educação contábil, Ensino da pesquisa contábil.

Muñoz, S., Ruíz, G. \& Sarmiento, H. (2015). Didácticas para la formación en investigación contable: una discusión crítica de las prácticas de enseñanza. En: Revista de la Facultad de Ciencias Económicas de la Universidad Militar Nueva Granada. rev.fac.cienc.econ, XXIII (1).

JEL: A20, M41.

\section{Introducción}

En las últimas tres décadas en Colombia se ha venido generalizando la preocupación y la discusión sobre la investigación contable, bien sea por los requerimientos de la acreditación de programas académicos (IFAC, 2008; Cardona \& Zapata, 2006) o por la inquietud de transformar la educación de los contables (Gracia, 2002; Quijano, 2004; Martínez, 2006), que ha estado caracterizada por la dominación de lo instrumental y acrítico de las relaciones contextuales (Rojas, 2009).

En esos años, la educación contable ha comportado unas transiciones vitales. Actualmente buena parte de los programas de contaduría pública en el país dejan entrever en sus estructuras curriculares algunas apuestas por la formación en otras disciplinas que dialogan con la contabilidad, así como contenidos de investigación; aunque aún no ha sido comprendida plenamente su potencialidad en la formación de contadores públicos, cuya profesión se ha tildado siempre de técnica-instrumental y de pocos fundamentos científicos. De todos modos, el hecho de que desde múltiples escenarios locales y externos (Colciencias, Unesco, Banco Mundial) se insista en la necesidad de impulsar la investigación en las universi- dades, ha generado una preocupación en torno a la investigación contable en los programas y facultades de contaduría pública, y representa un avance que no puede demeritarse, y que más bien debe reconocerse como un logro significativo para la educación, la disciplina y la profesión.

Las prácticas investigativas contables en Colombia han presentado en este tiempo unas características de necesaria mención: interdisciplinaria o al menos con el concurso de más de una disciplina distinta a la propia contabilidad, en alguna medida ha sido crítica de las relaciones sociales y políticas propias del capitalismo, con enfoques especialmente cuantitativos (IFAC, 2008), y con una evidente intención de hacer un reconocimiento de la contabilidad como disciplina social. Sin embargo, estas prácticas investigativas no se han desarrollado privilegiadamente en la universidad, apenas en los últimos años se han configurado múltiples grupos de investigación contable que han agenciado cantidades importantes de proyectos (Sarmiento \& Muñoz, 2011). También aquellas prácticas han adolecido de rigurosidad y diversidad metodológica (Gracia, 2002), asunto que en los últimos años ha venido mejorándose en los trabajos desarrollados por los grupos de investigación en las universidades, gracias a la formación de postgrado de los investigadores. 
A pesar de las dificultades, la investigación contable se ha venido perfilando como una estrategia pedagógica importante en la formación de contadores públicos (García, 2012, 158), para que ellos trasciendan las capacidades técnico-instrumentales y puedan enfrentar las demandas del contexto social y organizacional. No obstante, ésta no es aún una estrategia generalizada en todos los programas o facultades ni tampoco en todos los cursos del currículo; no obstante, cada vez se le reconoce más su necesidad y, por tanto, su obligada de-construcción epistémica y metodológica (Martínez, 2006). En este reconocimiento hay un aspecto que llama poderosamente la atención en este estudio: es común que en las propuestas curriculares la formación para la investigación se incluya dentro del componente de formación socio-humanística, por lo que se le asignan propósitos de formación relacionados con la escritura, el trabajo en equipo, la comprensión del entorno, la capacidad crítica y de transformación, entre otros; objetivos que suelen ser más centrales que la formación misma de investigadores para la contabilidad y las disciplinas sociales.

En la investigación contable que actualmente se hace en el país puede identificarse claramente los desplazamientos metodológicos y teóricos que se han logrado en los últimos años. Ya desde la década de 1970 se fue dotando a la educación contable de una fundamentación teórica a manera de cursos de teoría en los programas universitarios (Gómez, 2010); y en la última década se han venido consolidando algunos colectivos de investigación que han permitido la inclusión de perspectivas epistemológicas más diversas, tanto a la educación como a la misma práctica investigativa. No obstante, en la práctica educativa en las universidades, las dinámicas de investigación no capturan todavía los intereses de los estudiantes y difícilmente puede evidenciarse sus resultados en términos de formación humana, más allá de la producción intelectual de los estudiantes en congresos y otros eventos académicos.

Actualmente en las disciplinas sociales ya es un lugar común contextualizar las discusiones y formulaciones conceptuales a partir de las características del entorno social, y no sólo del conocimiento; no de otra manera se entendería que una ciencia social lo sea por derecho propio y sin consultar las complejidades de su objeto de estudio, y a esta premisa ha respondido la reflexión contable, sobre la base de la comprensión de la contabilidad como disciplina social (Larrinaga, 1999; Gray, 2002; Archel, 2007). Así, las dinámicas sociales, políticas y culturales delineadas desde hace algún tiempo por fenómenos como la globalización, la influencia de los medios de comunicación, el desarrollo permanente de tecnologías para la satisfacción de múltiples tipos de necesidades, la acentuación de las disparidades sociales, la complejidad de las relaciones sociales, etc. (Stiglitz, 2002; Naï, 2003; Beck, 2008; Harnecker, 2013), demandan de las disciplinas y las prácticas científicas, el desarrollo de arsenales conceptuales y metodológicos que contribuyan en la comprensión y transformación de los entornos (Morin, 1999; Bauman, 2009; Max Neef, 2013); y esta contribución es urgente, pues difícilmente la transmutación de realidades puede darse a partir de los conocimientos que han soportado las estructuras base de las relaciones actuales.

Este requerimiento también se le hace a la contabilidad; pues una vez superada la preeminencia de la visión ortodoxa de la contabilidad como sistema de información, ésta se vio obligada -al igual que otras disciplinas de su perímetro gnoseológico- a comprender los entornos sociales, políticos, económicos y organizacionales, para así formular conceptos, metodologías y procedimientos útiles y pertinentes para la transformación y el soporte de tales entornos (Ospina, 2005; Cortés, 2009). Y esa comprensión para la transformación, indefectiblemente debe basarse en la investigación, especialmente en una investigación que reconozca las relaciones de la contabilidad con otros campos de conocimiento y que privilegie la actitud crítica de los contables para asumir la comprensión de la complejidad inmersa en las relaciones contextuales de las organizaciones, el Estado, el ambiente y el conjunto de la sociedad (Giraldo, 2009; Patten, 2013; IAESB, 2014).

En la práctica profesional y en los escenarios nacionales de investigación contable se ha reconocido la necesidad de que el contable realice procesos de vinculación entre los conocimientos técnicos y los conceptos y teorías venidos de la contabilidad y otras disciplinas (Loaiza \& Rueda, 2011; Rueda \& Pinzón, 
2009) para que pueda generar alternativas desde el conocimiento e, incluso, para que pueda reconocer el lugar político de la disciplina y la profesión contables en contextos sociales y económicos determinados (Muñoz \& Sarmiento, 2010). A pesar de este reconocimiento, pareciera que la formación contable aún no ha dado pasos contundentes en este tránsito.

Podría evaluarse diversos aspectos de la educación contable, pero indiscutiblemente la formación en investigación ha sido uno de los componentes curriculares a los que más se le ha asignado la responsabilidad de producir tales aprendizajes y transformaciones, más allá de reconocer que la investigación contable empírica tradicional atiende esencialmente necesidades del entorno empresarial, pero no necesariamente contribuye a satisfacer otras demandas de mayor calado social y organizacional (Larrinaga \& Moneva, 2005; Pesqueux, 2009; Evans et al., 2014). Uno de los aspectos que debe revisarse al respecto de la investigación contable es su propia manera de enseñarse, la forma en que se inicia a los contables en los caminos de la investigación mediante la formación investigativa desde el currículo.

Sin embargo, dentro del contexto de la investigación educativa contable, es poco el aporte que hay acerca de las estrategias didácticas para la formación investigativa. Tal es el caso de los contextos internacionales, en los cuales de acuerdo con León (2009) se ha ido consolidando un capital simbólico que permite reconocer la investigación en educación contable como un campo de acción maduro y con reconocimiento social.

Una lectura detenida de las revisiones que en materia de investigación contable se han hecho en el contexto anglosajón, permite afirmar que el tema de las didácticas para la investigación contable no aparece como un tema relevante. En los exhaustivos trabajos de revisión sobre investigación en el campo de la educación contable emprendidos por Watson et al. (2007); Apostolou, Hassell, Rebele \& Watson (2010); y Apostolou, Dorminey \& Hassell (2013), no se le da a la enseñanza de la investigación un capítulo aparte dentro de las categorías de revisión. Dichos trabajos efectúan la revisión de una amplia cantidad de artículos sobre educación publicados en Issues in Accounting Education, Accounting Education: An International Journal, Advances in Accounting Education y Global Perspectives on Accounting Education. El análisis se hace sobre dos tipos de artículos: artículos empíricos que efectúan recolección y análisis de datos, y artículos descriptivos, ya sea de revisión de literatura o de descripción de un problema. En los tres casos reseñados, la revisión se hace en torno a las siguientes categorías: evaluación, plan de estudios e instrucción, tecnología educativa, asuntos atinentes a las facultades y estudiantes.

Dentro del análisis de la categoría plan de estudios $e$ instrucción, llama la atención que no se considera la enseñanza de la investigación como un asunto específico del currículo; a lo sumo se incluyen dentro del desarrollo de competencias básicas, al lado de las comunicativas y las sociales. En tanto, otro apartado habla de las áreas profesionales incluyendo la ética. La falta de investigaciones sistemáticas acerca del impacto de la enseñanza en la formación del contador, y específicamente de la enseñanza de la investigación contable, parece ser la norma, como se desprende de la conclusión de uno de estos estudios:

Mientras que la recolección de datos durante la evolución del semestre académico plantea muchos retos, entre los cuales la deserción escolar es no menos importante, los estudios a largo plazo proporcionan la evidencia más confiable del currículo y de la eficacia pedagógica. Por ejemplo, los estudios de caso pueden ayudar a los estudiantes a entender el material proporcionado y a tener un mejor desempeño en las pruebas del semestre; pero sería necesario preguntarse si en un curso futuro, ¿̇serían capaces esos estudiantes de recordar la información aprendida haciendo estudios de caso? Un curso de escritura intensiva o una propuesta de fortalecimiento escritural puede mejorar la escritura en un curso, pero ċse dará también esa mejora en semestres futuros? (Watson et al., 2007, 22).

Las discusiones sobre investigación se presentan específicamente en la categoría de asuntos relacionados con las facultades. Básicamente, se relacionan con los índices de productividad investigativa y su incidencia en los procesos de acreditación de las facultades y de los profesores. En este sentido, los tra- 
bajos sobre investigación contable que aparecen reseñados, se orientan a analizar los factores de mayor o menor productividad investigativa en el contexto de las necesidades de acreditación de las facultades; todo lo cual es la expresión del proceso de mercantilización de la investigación superior que ha conducido e establecer una brecha entre la investigación y la formación del contador público (Cullen, Richardson \& O’Brien, 2004; St. Pierre et al., 2009).

Para St. Pierre et al. (2009), a pesar de que la investigación es inherente a la formación en educación superior, en el campo de la formación contable se evidencia cierto desdén frente al tema; el autor atribuye el hecho a que las investigaciones en el campo de la educación contable no gozan del mismo reconocimiento que las de otros campos tales como los de regulación contable, y a la negación de algunos editores a publicar artículos sobre educación contable, con el supuesto de que estos disminuyen la calidad editorial de las revistas.

A esto se suma la ausencia de propuestas teóricas que orienten la enseñanza de la investigación en el campo contable, lo cual exige replantear las concepciones acerca del vínculo entre la investigación y la docencia y las concepciones acerca de la investigación, la enseñanza y el aprendizaje (Healey, 2005, citado por Jalbert, 2008).

De allí que una revisión de la didáctica de la enseñanza de la investigación contable debe considerar, entre muchos, aspectos como: los conceptos centrales que se discuten (también los que no se discuten) en los procesos de formación investigativa, los modelos explicativos utilizados para ello, los presupuestos epistémicos y prácticos que se utilizan para construir los conceptos, el contenido y los objetivos de la formación investigativa, los procesos y las consideraciones epistémicas de la formulación de problemas de investigación, las metodologías de evaluación y autorregulación de los aprendizajes, etc.; aspectos todos estos en los que no se implican dimensiones exclusivas del conocimiento, sino que intervienen asuntos incluso de lo cultural de los sujetos y las instituciones. Según Tamayo (2003), en una reflexión sobre la didáctica tendrán que asumirse los problemas desde miradas multidisciplinarias que integren dimensiones de lo humano, social, cultural, político y tecnológico.

Esta vía de comprensión de la didáctica puede encontrarse en la propuesta de la didáctica crítico constructiva de Wolfgang Klafki (1986), en la que el eje de discusión se ubica en lo formativo que tienen los contenidos seleccionados en un proceso de formación (Runge, 2008, 169). Esta reflexión en torno a los aspectos formativos que subyacen en las didácticas de investigación es una labor que trasciende el campo disciplinar de la didáctica y se vincula estrechamente con la pedagogía, en la medida en que se pregunta por el tipo de sujeto que se desea formar. En este sentido, si bien el interés del actual proyecto se manifiesta claramente sobre lo didáctico, responder a estas inquietudes tendrá que pasar por la reflexión pedagógica.

De allí que las indagaciones didácticas no solo deben abarcar las decisiones acerca de la manera más eficiente para lograr los objetivos de aprendizaje, sino que debe preocuparse también por la pertinencia de estos objetivos, por las implicaciones que estos tienen en relación con la formación de un contador público que reconozca las relaciones sociales, políticas y económicas en las cuales se desarrolla su quehacer profesional y se moviliza el conocimiento contable, asunto que concierne a la pedagogía.

Si es admitida la necesidad de la investigación contable y-aunque no de manera generalizada- se reconozca que el rol contable puede tener mayores implicaciones en la dinámica de lo social y lo económico, en ámbitos de lo público tanto como de lo privado; entonces resulta pertinente preguntarse el porqué del bajo impacto de la formación investigativa y de las dinámicas de investigación en el campo contable en Colombia, en términos de la cantidad de estudiantes y egresados que hacen investigación, y el avance en el desarrollo del potencial crítico, argumentativo, escritor, propositivo con el ámbito organizacional y social, transformador de sus contextos, o al menos preocupado en su discurso por las implicaciones sociales de la praxis contable. Es por esto que en este documento se discuten tópicos relacionados con las perspectivas didácticas privilegiadas en la enseñanza de la investigación en programas de contaduría 
pública en la ciudad de Medellín, y la lectura que de estas puede hacerse desde la didáctica crítico constructiva de Klafki.

\section{Explicitación del método}

\subsection{Justificación epistémica del método}

El horizonte epistémico del estudio del que se deriva este artículo se ubica en la pedagogía crítica alemana, la cual propone que el proceso educativo debe procurar efectos profundos en el sujeto, tales como la conciencia, la autonomía y la crítica frente a las relaciones de dominación de las sociedades. Y en el amplio espectro de esta pedagogía, esta investigación bebe específicamente de la didáctica crítico-constructiva de Klafki (1986), en la cual la didáctica se asume como el conjunto de decisiones que vincula estrechamente los fines formativos, con los contenidos y las estrategias necesarias para lograr tales propósitos. En consecuencia, la lectura que pueda hacerse de la pertinencia de esta propuesta metodológica, debe acompasarse con la plena comprensión del marco teórico-conceptual de esta importante tendencia del pensamiento pedagógico contemporáneo.

El interés práctico del estudio es explicativo $e$ interpretativo de las didácticas aplicadas en los procesos de formación en investigación, y se nutre de la propuesta de la didáctica de Klafki $(1986,48)$ en la medida en que plantea que la educación debe potenciar la autodeterminación, codeterminación y solidaridad del sujeto, asuntos que aparecen recurrentemente como objetivos de la formación sociohumanística, dentro de la que se ubica comúnmente la investigación contable, y por ello a ésta se le asignan los mismos propósitos.

En general las organizaciones y algunos profesores atribuyen a los estudiantes y profesionales de la con- taduría pública un escaso potencial investigativo, argumentativo, escritural, crítico y propositivo, ${ }^{1}$ asuntos que se han creído vinculados con la formación sociohumanística e investigativa; por lo que en este estudio se indagó por la responsabilidad que tendría la didáctica de la formación para la investigación frente a esas situaciones. Más allá de este análisis, que corresponde a una mirada lógica causal -aunque más justificativa que determinística- ${ }^{2}$, el proyecto buscó caracterizar comprensivamente las didácticas de la formación para la investigación, mediante la construcción de una interpretación del carácter formativo, tanto de los propósitos de formación como de los contenidos y las metódicas -conceptualmente diferenciadas por Klafki (1986), del método y las metodologías que se implican en la didáctica- para acceder a los mismos en la formación investigativa contable.

Esa caracterización comprensiva se hace necesaria para el estudio, por la consideración de que la experiencia humana y social resulta ser un entramado de significaciones que no necesariamente son transparentes ante la razón, pero que sí emerge en las distintas posibilidades del lenguaje, por lo que éste cumple al tiempo el papel de objeto y mediador de la experiencia (Alvarado \& Ospina, 2009). El ser humano permanentemente interpreta, en su tarea del comprender primario al que aludía Heidegger, como la captura mental del sentido de las cosas; pero no en esa primera anticipación inmediata se agota el sentido de la experiencia humana, aunque en todo caso actúe como un haber inicial para la interpretación (Herrera, 2010).

El papel de la interpretación en este estudio tiene que ver con la explicitación de un sentido de la experiencia docente, con base en dos instancias fundantes: la narración de los sujetos y el contexto institucional que enmarca su experiencia, aunque este último se

1 Al menos en Colombia, buena parte de los diagnósticos presentados en los encuentros nacionales de profesores de Contaduría Pública y congresos de contadores públicos e investigadores contables, así como los informes oficiales sustentados en las pruebas de estado Saber Pro, coinciden en señalar estas deficiencias formativas, como factores determinantes de un desempeño profesional poco destacado.

2 Pues habría necesidad de otra clase de estudio, quizá más de corte etnográfico, en el que se acuda directamente a la población estudiantil, para afirmar que hay una relación causal incuestionable entre un tipo de didáctica y las características subjetivas de los estudiantes; con lo abordado en esta investigación, a lo sumo podría inferirse una explicación racional (justificación) entre las propiedades de la didáctica y la forma en la que profesores e instituciones entienden que ésta impacta a sus estudiantes. 
aborde solamente en el escenario más inmediato de actuación, que son los programas de formación contable; dado que la acción de los sujetos, así como la interpretación que ellos $\mathrm{u}$ otros pueden hacer de la misma no puede deslindarse de sus contextos particulares de actuación (Alvarado \& Ospina, 2009), los cuales están configurados tanto por su experiencia personal, como por las condiciones históricas del espacio que habita.

Para la construcción de la interpretación, en este estudio se consideraron imprescindibles -como punto de partida- las preguntas por lo que se enseña, el cómo se enseña y el para qué se enseña, por dos razones fundamentales: la primera, porque de acuerdo con Klafki (1986) la reflexión didáctica no puede centrarse en las intencionalidades formativas de unos contenidos separadamente de las formas en que estos son abordados o enseñados; y segunda, porque esas preguntas configuran la puerta de entrada a la experiencia docente del enseñar investigación contable, ya que con base en estas explicitaciones iniciales de sentido se ubican los caminos categoriales para la comprensión -ya no primaria- de las didácticas utilizadas por los profesores.

Con base en el reconocimiento de que la investigación comprensiva o cualitativa no busca generalizaciones ni proponer fórmulas prediseñadas a las prácticas sociales (Morse, 2006; Galeano, 2004; Bonilla-Castro \& Rodríguez, 1997), en este estudio no se partió de marcos teóricos preestablecidos para guiar deductivamente el tratamiento a la información, ni se optó por una recolección estadísticamente representativa de datos; sino que se apeló a una perspectiva pedagógica concreta para que actuara como referente epistémico, y se abordó la experiencia de algunos profesores de contados programas de contaduría pública de Medellín, cuyas narrativas se trataron esencialmente de manera inductiva, en diálogo con referentes conceptuales y teóricos útiles a fines de leer críticamente en contexto las didácticas.

Por lo anterior, la apuesta teórica y práctica de esta investigación estuvo abierta a la caracterización didáctica de la formación para la investigación en programas de contaduría pública de universidades de la ciudad de Medellín, lectura que se hizo desde la perspectiva de la institución y de los profesores, por la consideración de que la enseñanza es una de las dimensiones del proceso educativo, cuyo diseño corresponde inicialmente a la institución y al profesor; es decir, el alcance de este estudio se ubica en las declaraciones institucionales y la experiencia narrada por los profesores, no en la validación de las mismas en la experiencia de los estudiantes, lo que podría ser objeto de otro estudio.

Apoyada en la didáctica crítico-constructiva de Klafki (1986), la búsqueda de información y de sentido se fundó en la experiencia de los siguientes actores: para obtener la perspectiva pedagógica institucional sobre la investigación contable, se acudió a los directores de programa y coordinadores de investigación; para decantar la mirada más didáctica se interactuó con los profesores que orientan y acompañan los procesos de formación para la investigación. Las indagaciones se centraron en tres aspectos, tanto de la propuesta curricular como de las prácticas docentes que los profesores explicitan, a saber: primero, las intencionalidades generales con las cuales se incluyen los cursos de investigación en los planes de estudio, así como las particulares que plantean los profesores de investigación para sus cursos; segundo, los contenidos abordados en los cursos de investigación, de acuerdo con lo enunciado por los profesores y lo puntualizado en las cartas descriptivas de los cursos (lo cual reúne tanto la exigencia institucional como el interés del profesor); y, finalmente, las metódicas (estrategias metodológicas) que los profesores dicen que utilizan para enseñar tales contenidos.

\subsection{Operacionalización metodológica}

\subsubsection{Primer momento: identificación de los programas sobre los cuales se hizo el estudio}

Se realizó inicialmente un mapeo de las propuestas curriculares de contaduría pública en Medellín, a partir de la información disponible en las páginas web, centrando la atención en la existencia de formación para la investigación en los mismos, tanto en cursos como en semilleros, grupos y líneas de investigación, $\mathrm{u}$ otros espacios que permitieran la participación de estudiantes en procesos investigativos. 
En este momento se hizo una primera etapa de recolección de información: el mapeo de las generalidades de los programas, como perfiles, propósitos de información, créditos y cursos de investigación, grupos y semilleros de investigación, etc., necesario para la selección de los programas a estudiar.

De casi veinte programas en la ciudad, se seleccionaron siete de acuerdo con los siguientes criterios(cuyo incumplimiento, con excepción del primero, no actuó como factor de exclusión de alguna universidad): existencia del eje o componente de formación en investigación en el plan de estudios, existencia de grupo y semilleros de investigación en contabilidad, acreditación de alta calidad del programa, cantidad relevante de créditos o cursos de investigación, disponibilidad de información en la página web institucional y disposición de la institución para facilitar el acceso a la información.

Los programas seleccionados pertenecen a las siguientes universidades, que serán expuestas en orden alfabético, con el ánimo de que no se asuma ningún tipo de jerarquía:

- Corporación Universitaria Remington.

- Fundación Universitaria Luis Amigó.

- Politécnico Colombiano Jaime Isaza Cadavid.

- Universidad Autónoma Latinoamericana

- Universidad de Antioquia.

- Universidad de San Buenaventura sede Medellín.

- Universidad Eafit.

\subsubsection{Segundo momento: recolección de la información}

Para la recolección de la información se diseñaron dos rutas: una primera ruta participativa, en la que se realizaron entrevistas semi-estructuradas con los directores de programa y los coordinadores de investigación de cada una de estas universidades, así como dos grupos focales con dos profesores de cada programa, que orientan cursos de investigación y afines, o que también desarrollan procesos de investigación contable. A directores y coordinadores se les indagó por generalidades de los programas, los propósitos de la formación en investigación en los mismos, sus convicciones con respecto a la investigación contable, entre otros asuntos; mientras que a los profesores se les indagó puntualmente por aspectos relacionados con las didácticas empleadas en el proceso de enseñanza de la investigación contable: el propósito de tal formación, el contenido abordado en los cursos y las estrategias empleadas (para problematizar la realidad, para conceptualizar, para acercar a los estudiantes a los métodos de investigación, entre otros).

Otra ruta de revisión documental, en la que se avanzó en el análisis didáctico de las cartas descriptivas de los cursos orientados por los profesores participantes en los grupos focales, siguiendo la propuesta de Klafki (1986) para este tipo de ejercicio interpretativo.

\subsubsection{Tercer momento: caracterización comprensiva de las didácticas}

La construcción y análisis de la información para la caracterización didáctica tuvo varias etapas, correspondientes con las rutas de recolección: la primera consistió en la construcción de una matriz para la identificación de la idea de investigación de los programas seleccionados, con base en los datos disponibles en la página web y las declaraciones de directores de programa y coordinadores de investigación.

En la segunda ruta se dieron dos procesos paralelos: por un lado, se hizo el análisis didáctico de las cartas descriptivas de los cursos de investigación que fueron aportadas por las universidades; y por el otro lado, se abordó la información de los grupos focales, identificando alusiones de los participantes de acuerdo con la siguiente categorización de partida: el para qué (dimensión teleológica) de la formación para la investigación, el cómo (dimensión metodológica) de esa formación y el qué (dimensión ontológica - contenidos) de la misma.

A partir de la anterior organización, se produjo una codificación detallada dentro de tales categorías de entrada, para luego construir las categorías de análisis y construcción interpretativa, que se presentarán en la siguiente sección, siguiendo la Tabla 1. 
Tabla 1. Codificación categorías de análisis ${ }^{3}$

\begin{tabular}{|c|c|c|c|c|}
\hline \multirow{8}{*}{$\begin{array}{l}\text { Entrada a la información: } \\
\text { categorías descriptivas }\end{array}$} & \multirow{3}{*}{$\begin{array}{l}\text { 1. Idea institucional de investi- } \\
\text { gación y el potencial formativo } \\
\text { de la investigación }\end{array}$} & \multicolumn{3}{|c|}{ La investigación en función de la formación integral } \\
\hline & & \multicolumn{3}{|c|}{ La investigación como didáctica } \\
\hline & & \multicolumn{3}{|c|}{ La investigación como solución propedéutica } \\
\hline & \multirow{5}{*}{$\begin{array}{l}\text { 2. Miradas de los profesores } \\
\text { sobre su práctica docente en } \\
\text { investigación }\end{array}$} & \multicolumn{3}{|c|}{ Lo prometido en los microcurrículos } \\
\hline & & \multirow{4}{*}{$\begin{array}{l}\text { La narración de la expe- } \\
\text { riencia de los profesores }\end{array}$} & \multirow{2}{*}{$\begin{array}{l}\text { - Lo que dicen de } \\
\text { las intencionalida- } \\
\text { des formativas: el } \\
\text { para qué }\end{array}$} & $\begin{array}{l}\text { - El estudiante como sujeto de } \\
\text { formación }\end{array}$ \\
\hline & & & & $\begin{array}{l}\text { - El profesor como sujeto portavoz } \\
\text { de la disciplina }\end{array}$ \\
\hline & & & \multicolumn{2}{|c|}{ - Lo que dicen de sus estrategias metodológicas: el cómo } \\
\hline & & & \multicolumn{2}{|c|}{ - Lo que dicen de los contenidos de formación: el qué } \\
\hline \multirow{6}{*}{$\begin{array}{l}\text { Construcción interpre- } \\
\text { tativa: categorías com- } \\
\text { prensivas. }\end{array}$} & \multirow{2}{*}{$\begin{array}{l}\text { 1. La presencia de lo socio- } \\
\text { humanístico }\end{array}$} & \multicolumn{3}{|l|}{ Lo social naturalizado } \\
\hline & & \multicolumn{3}{|c|}{ Tensión entre dos comprensiones de lo social } \\
\hline & \multirow{3}{*}{ 2. El papel del profesor } & \multicolumn{3}{|l|}{ Como motivador } \\
\hline & & \multicolumn{3}{|l|}{ Como experto } \\
\hline & & \multicolumn{3}{|l|}{ Como asesor - modelo } \\
\hline & \multicolumn{4}{|l|}{ 3. La ausencia de la crítica } \\
\hline
\end{tabular}

\section{Discusión de resultados y referentes}

En toda discusión que aborde el tema educativo aparece la pregunta por la formación, de hecho, en muchos espacios llegan a equipararse ambos términos (educación y formación). Por no ser la intención de este documento presentar una disquisición amplia y profunda al respecto, basta aquí acudir a una mirada sobre la formación, que actúe no sólo como faro para comprender las implicaciones de la lectura didáctica que aquí se presenta, sino que además resulte coherente con la perspectiva epistémica de la didáctica crítico-constructiva.

A este fin, conviene entender la formación como la instancia unificadora del principio de humanización y el eje teórico de la pedagogía. Dentro de la antropología pedagógica, formación es diferente de educación: mientras la primera es un concepto inmanente, que conduce a la idea de la autorrealización y el devenir permanente del sujeto, la segunda es un proceso externo de influencia sobre él (Runge
\& Garcés, 2011). En este sentido, la pedagogía tiene dos posibles enfoques: unas teorías de la educación y otras de la formación. "En un sentido amplio, las primeras responden al 'cómo' y las segundas al 'qué' y al 'para qué” (Runge \& Garcés, 2011, 16). Así, se asume la formación como "el proceso de despliegue del ser humano en medio del mundo cultural y espiritual" (Runge, 2011); por tanto, ese proceso se concibe como un producto basado en la idea de sujeto, que lo faculta para darse forma de acuerdo con sus propias potencias e intereses personales.

En consonancia con esta idea de formación que alude a la configuración de subjetividad, para Klafki (1986) la didáctica es un acto reflexivo de toma de decisiones en torno a los fines de los contenidos educativos. Hay una primacía de los fines que determina la elección y organización de los contenidos en función de éstos; pero esta relación no es lineal ni mecanicista, pues la determinación de los fines no implica que los contenidos se conviertan en un medio para llegar a esos fines. Se trata más bien de

3 Fuente: Elaboración propia. 
pensar asuntos como: cuál es el poder formativo de los contenidos y de qué manera se insertan estos en el entramado social del sujeto que se forma; cuáles contenidos tienen un matiz emancipador, en tanto ponen en cuestión las condiciones sociales de producción del conocimiento, superando la ilusión de neutralidad; y cuáles, pese a su matiz instrumental, pueden abordarse de una forma crítica a partir de la metódica, teniendo en cuenta que ésta también puede reproducir aquellas prácticas sociales que se desean transformar y que la elección de los medios presupone un criterio de selección que limita y posibilita el alcance de ciertos fines.

Es por eso que este es un estudio didáctico, en tanto implica un proceso de descripción, explicación e interpretación en dos posibles sentidos: el primero y más intuitivo significado de lo didáctico se relaciona con el análisis de aquellos métodos que se aplican para desarrollar en los estudiantes el espíritu y la potencia para hacer investigación contable. Pero, de acuerdo con la pedagogía crítica y específicamente la propuesta crítico-constructiva de Klafki (1986), la reflexión didáctica no puede agotarse ni en las metódicas ni en la explicitación de los fines formativos; de ahí que el estudio manifieste un segundo sentido didáctico preocupado por la relación entre estos fines, los contenidos seleccionados para lograrlos y las metódicas decididas para ello.

Es claro que el segundo sentido de lo didáctico enunciado no controvierte el primero, sino que más bien lo profundiza, pues de acuerdo con Klafki (1986) la reflexión didáctica trasciende la preocupación por los objetivos de formación explícitos al interesarse también por los implícitos.

El carácter 'crítico' de la didáctica de Klafki (1986, 42) está relacionado con potenciar "la autodeterminación, codeterminación y solidaridad en todas las dimensiones de la vida", mientras que el carácter 'constructivo' se refiere a la continua relación que se presenta entre lo práctico y lo teórico, en la que hay una cooperación que permite generar reflexión.

Para el autor, la didáctica en sentido amplio surge como resultado de la investigación acerca de: los objetivos o propósitos de la enseñanza, los contenidos, las formas de organización y realización (en las que la relación entre procesos de enseñanza y aprendizaje debe ser entendida como una relación de interacción) y los medios. Los dos primeros elementos configuran lo que Klafki (1986) denomina didáctica en sentido estrecho y a los dos últimos los asocia con el objeto de estudio de la metódica. En esa vía, este estudio se orienta hacia la integración de estos conceptos: una didáctica en sentido amplio que indague por los fines explícitos e implícitos de los temas y organización de los mismos en los cursos de formación para la investigación contable, y una metódica que indague por los medios y fines utilizados para tal fin.

Con esta premisa, se discuten a continuación tres niveles de organización, descripción e interpretación de la información suministrada y construida en el estudio. El primero alude a la forma en que se propone curricularmente la formación investigativa, es decir, lo hallado en los programas, sin ponerlo aún de frente con la mirada interpretativa; el segundo propone una descripción crítica de las propuestas microcurriculares de los cursos de investigación, así como una discusión crítica del qué, el cómo y el para qué de tales cursos; y el tercero presenta una mirada interpretativa del mundo y el sujeto del que hablan estos cursos de formación investigativa.

\subsection{Postulación institucional de la formación para la investigación: la organización curricular y las miradas sobre la investigación}

En los programas seleccionados se encontró que la formación para la investigación se da en espacios escolarizados y no escolarizados. Los primeros son esencialmente los cursos de investigación, que tienen diferentes intencionalidades, cantidad de créditos y cursos, y ubicaciones en los planes de estudio, entre los distintos programas. Los segundos son esencialmente los semilleros de investigación, los cuales no son objeto de análisis de este estudio.

En la mayoría de los programas, la formación para la investigación se incluye dentro del componente socio-humanístico, el cual pretende dotar a los estudiantes de elementos provenientes de las ciencias humanas y sociales, para que pueda actuar en todos 
los escenarios organizacionales, atendiendo a unas premisas de la ética profesional y la moral social; de ello se deriva que la formación para la investigación tendría como primeros propósitos la potenciación de actitudes y aptitudes referidas a la subjetividad y la intersubjetividad. Esto resulta cuando menos curioso, una vez que tradicionalmente la investigación es considerada en primera medida una práctica científica y académica, de la que en todo caso pueden esperarse otros resultados, pero esencialmente se le plantean compromisos con la producción, reproducción y ampliación de los límites de los campos de conocimiento.

En sintonía con esos propósitos, la mayoría de esos programas proponen en su perfil, y lo ratifican los directores de programa, a un contador profundamente conocedor de los ámbitos organizacional y social, problematizador y crítico de la realidad, propositivo en las organizaciones; al tiempo que le delinean -también como promesa- un desempeño profesional especialmente en la empresa, encargado de la confección de información contable, financiera y tributaria.

Los programas de contaduría pública plantean que la formación para la investigación no es exclusiva de los cursos relacionados directamente con la investigación, sino que se vincula estrechamente con la fundamentación contextual, teórica y epistemológica, así como con las potencialidades comunicativas; lo cual en alguna medida ha correspondido a la demanda que desde diversos escenarios se ha hecho sobre ese necesario vínculo entre teoría e investigación (Loaiza \& Rueda, 2011; Rueda \& Pinzón, 2009).

La preocupación por establecer vínculos entre la teoría y la investigación, como expresión de lo práctico, es recurrente en el contexto anglosajón. Se evidencian varios proyectos que intentan la vinculación entre el conocimiento teórico y la práctica. En el caso de la ética, por ejemplo McPhail (2005) discutió un proyecto de servicio a la comunidad para un curso de Ética Contable y los Negocios que introduce a los estudiantes al trabajo en beneficio del público, para alentarlos a considerar el interés público. Esta referencia permite pensar la posibilidad de que el desarrollo formativo de los estudiantes, específicamente en torno a un pensamiento social, puede lograrse si se establece un vínculo más preciso entre la teoría contable y los escenarios de organización en los cuales se desenvuelve la contabilidad, mediante el estímulo a la investigación empírica.

En ese sentido, la investigación emprendida por Cullen et al. (2004) llega a la conclusión de que los educadores deben incorporar casos empíricos en el plan de estudios de contabilidad para desarrollar en los estudiantes habilidades de investigación, en lugar de que estos permanezcan inactivos en las revistas de investigación. De esta forma, la investigación y la educación aparecen como inextricablemente vinculadas.

No obstante, esta afirmación no puede entenderse como una exacerbación del trabajo empírico en detrimento del teórico, y mucho menos de la experiencia laboral como el único criterio válido para definir aspectos prácticos y metodológicos propios de la investigación. Específicamente se invita a trascender la metodología de casos centrada exclusivamente en el método Harvard, para asumir unos casos más "sucios", en los cuales prime la complejidad de la realidad y puedan conducir a interpretaciones más ricas a partir de diversos marcos de referencia y de esta forma superar la tendencia gerencialista que se le ha dado a la contabilidad (Cullen, et al., 2004); pues como bien afirma el estudio de Ballantine \& McCourt (2004), no es necesario tener experiencia laboral en el campo contable para planificar estudios de caso, yendo más allá al evidenciar que los estudiantes con mayor fortaleza en acercamientos teóricos tienen mayor capacidad para formular, sintetizar y proponer múltiples soluciones a un problema.

En la lectura de los programas que hizo este estudio, se clasifican los cursos directos o relacionados con la formación para la investigación en tres grupos: el primero, los cursos de fundamentación, en el que se incluyen los que proveen contenidos fundamentales del pensamiento contable, teoría y epistemología contable en los primeros niveles, otras áreas de la contabilidad que amplían la perspectiva disciplinar, y los dirigidos a las potencialidades comunicativas. El segundo grupo reúne los cursos que abordan los aspectos propios de la investigación, como la formulación de proyectos, los asuntos del método, los refe- 
rentes, entre otros, tengan o no involucrado un ejercicio investigativo de corto alcance. Y al tercer grupo corresponden los cursos de finalización de programa, en los que se ponen en práctica los aprendizajes de investigación, en la realización de una monografía o la participación como auxiliar en un proyecto de investigación (Tabla 2).

La organización de los cursos no es uniforme en los programas, pero sí pueden hallarse unas situaciones comunes: casi que en la mitad de los programas, los cursos de formación metodológica están ubicados en el plan de estudios antes que los cursos de fundamentación; en la otra mitad, pasa justo lo contrario. Esta situación quizá tenga implicaciones directas con los logros y dificultades para los procesos de problematización de la realidad, formulación de problemas de investigación contable y conceptualización, básicos todos en la práctica investigativa. Los programas que tienen primero en su estructura curricular los

Tabla 2. Clasificación de los cursos relacionados con investigación en cada programa ${ }^{4}$

\begin{tabular}{|c|c|c|c|}
\hline UNIVERSIDADES & CURSOS DE FUNDAMENTACIÓN & $\begin{array}{l}\text { CURSOS DE FORMACIÓN } \\
\text { METODOLÓGICA }\end{array}$ & $\begin{array}{l}\text { CURSOS DE PRACTICA } \\
\text { INVESTIGATIVA }\end{array}$ \\
\hline \multirow[t]{2}{*}{$\begin{array}{l}\text { Corporación Universitaria } \\
\text { Remington }\end{array}$} & $\begin{array}{l}\text { Paradigmas y programas de investigación } \\
\text { - Competencias Comunicativas } \\
\text { Teoria contable } \\
\text { - Teoria contable } 2\end{array}$ & $\begin{array}{l}\text { Metoddogia de la investigación } \\
\text { contable } \\
\text { Seminario de investigación contable } \\
\text { Seminario de investigación I }\end{array}$ & \\
\hline & 4 cursos - 11 créditos & 3 cursos - 9 créditos & \\
\hline \multirow[t]{2}{*}{$\begin{array}{l}\text { Fundación Universitaria } \\
\text { Luis Amigó }\end{array}$} & $\begin{array}{l}\text { Historia de la contaduria pública } \\
\text { Epistemologia de la contabilidad } \\
\text { Teoria del saber contable } \\
\text { Conocimiento organizacional } \\
\text { - Gestión y contabilidad social y ambiental }\end{array}$ & $\begin{array}{l}\text { - Generalidades del proceso de } \\
\text { investigación y construcción de } \\
\text { objetos de estudio } \\
\text { Construcción teorica en procesos de } \\
\text { investigación } \\
\text {. Diseño metodológico }\end{array}$ & $\begin{array}{l}\text { Monografia I } \\
\text { Monografia II }\end{array}$ \\
\hline & 5 créditos -10 créditos & 3 cursos -6 créditos & 2 cursos -4 créditos \\
\hline \multirow[t]{2}{*}{$\begin{array}{l}\text { Politécnico Colombiano } \\
\text { Jaime Isaza Cadavid }\end{array}$} & $\begin{array}{l}\text { - Lengua matema } \\
\text { - Introducción al área profesional } \\
\text { - Teoria contable }\end{array}$ & $\begin{array}{l}\text { Fundamentos de investgación } \\
\text { - Investigación contable }\end{array}$ & $\begin{array}{l}\text { Consultorio Contable } \\
\text { (aunque no todas las } \\
\text { modalidades de trabajo de grado } \\
\text { scn irvestigativas) }\end{array}$ \\
\hline & 3 cursos -8 créditos & 2 cursos - 5 créditos & 1 curso - 8 créditos \\
\hline \multirow[t]{2}{*}{$\begin{array}{l}\text { Universidad Autónoma } \\
\text { Latinoamericana }\end{array}$} & $\begin{array}{l}\text { Habilidades comunicativas } \\
\text { - Fundamentos de pensamiento contable } \\
\text { - Epistemologia e historia contable } \\
\text { - Teoria contable } \\
\text { Contabilidad social y ambiental } \\
\end{array}$ & $\begin{array}{l}\text { - Seminario de investigación I } \\
\text { - Seminario de investigación II }\end{array}$ & $\begin{array}{l}\text { Opción de Grado I } \\
\text { Opción de Grado II } \\
\text { (aunque no todas las } \\
\text { modalidades de trabajo de } \\
\text { grado son investigativas) }\end{array}$ \\
\hline & 5 cursos -16 créditos & 2 cursos - 5 créditos & 2 cursos -12 créditos \\
\hline \multirow[t]{2}{*}{ Universidad de Antioquia } & $\begin{array}{l}\text { - Cultura Contable } \\
\text { Teoria Contable } \\
\text { - Estructura Contable } \\
\text { - Funda. Interdisciplinar Contabilidad } \\
\text { - Interdisciplinar Ente económico } \\
\text { - Taller Lecto Escritora } \\
\text { - Taller de Retórica y Argumentación } \\
\text { - Modelación Contable } \\
\end{array}$ & $\begin{array}{l}\text { Semillero de Investigación I } \\
\text { Semillero de Investigación II } \\
\text { - Metodologia de Investigación } \\
\text { Contable }\end{array}$ & $\begin{array}{l}\text { - Trabajo de Grado I } \\
\text { - Trabajo de Grado II }\end{array}$ \\
\hline & 8 cursos -26 créditos & 3 cursos -7 créditos & 2 cursos -5 créditos \\
\hline \multirow{2}{*}{$\begin{array}{l}\text { Universidad de San } \\
\text { Buenaventura } \\
\text { sede Medellin }\end{array}$} & $\begin{array}{l}\text { - Competencias Comunicativas } \\
\text { - Epistemología de la contabilidad }\end{array}$ & $\begin{array}{l}\text { - Investigación I } \\
\text { - Investigación II }\end{array}$ & - Trabajo de grado \\
\hline & 2 cursos - 5 créditos & 2 cursos -6 créditos & 1 curso - 2 créditos \\
\hline \multirow{2}{*}{ Universidad Eafit } & Análisis textual & - Teoria e investigación contable & \\
\hline & 1 curso -3 créditos & 1 curso -3 créditos & \\
\hline
\end{tabular}

4 Fuente: Elaboración propia de acuerdo con información disponible en páginas web de los programas y las cartas descriptivas aportadas por los mismos. 
cursos de fundamentación, tienen menos dificultades para lograr la formulación de problemas contables en los cursos de ejercicio investigativo.

Resulta particular que no todas los programas plantean cursos de formación en asuntos escriturales, pero sí todos declaran, en sus perfiles o en lo expuesto por directores, coordinadores o profesores, que ese es uno de sus objetivos principales en la formación para la investigación. Merece una mención especial el hecho de que en una de las universidades aparezca como curso de fundamentación la formación en retórica y argumentación, pues ésta potencialidad también es declarada por los profesores como una de las promesas formativas de la investigación.

Desde la perspectiva más institucional, manifiesta en la información disponible al público en la página web y lo expresado por los directores de programa y los coordinadores de investigación, para la educación en contaduría pública la investigación representa dos situaciones, o tiene dos razones de ser: de un lado, la investigación es una función del programa, porque esa es una de las responsabilidades de la educación superior; y por el otro lado, el potencial formativo de la investigación.

Sobre el primer sentido, es factible leer en lo explicado por los directores de programa y coordinadores de investigación que actualmente la investigación existe en la educación contable -quizá en otros campos también- atendiendo más a una presión institucional que a las propias urgencias de la disciplina y el papel social de la profesión; en este sentido, la investigación resulta ser un indicador de cierto tipo de productividad institucional, pues los requerimientos estatales y de las comunidades académicas fuerzan constantemente y cada vez más la publicación de artículos en revistas indexadas y, en general, por la satisfacción de los cánones tradicionales de las ciencias exactas, que parecieran ser los privilegiados por organismos como Colciencias.

También en este sentido de la investigación como función del programa, apareció una marcada preocupación, especialmente en coordinadores de investigación y profesores, por las dificultades para construir comunidad académica contable, asunto que desvanece en alguna medida los esfuerzos atomizados por ampliar los horizontes del conocimiento contable y las posibilidades de que éste transforme las prácticas.

Con respecto al segundo sentido, el potencial formativo de la investigación, podría decirse que para los programas en general, la investigación se postula como un camino y un fin formativo, que cumple diversos papeles dentro del programa y el proceso educativo, a saber:

- La investigación en buena medida se piensa en función de la formación integral, lo cual a primera vista resulta plausible; en todo caso, de esta relación habría que evaluar con más detenimiento el sentido que le asignan los programas a esa integralidad, pues en las declaraciones de directores de programa, coordinadores y profesores, así como las informaciones públicas de las universidades, se lee la integralidad aplicable al mejoramiento del perfil profesional, $y$ no tan ocupado de la formación en lo humano. En los enunciados de directores y profesores, resulta más central la postulación de la investigación como una estrategia que permite formar en aspectos subjetivos e intersubjetivos, que su potencial para ampliar los horizontes del propio campo de conocimiento.

- La investigación como didáctica es común en la mayoría de los programas, especialmente en los que se apuesta por el aprendizaje colaborativo y significativo, pues se enuncia que la investigación es una estrategia privilegiada para la formación en los demás campos. Sin embargo, los mismos profesores enuncian las dificultades para establecer relaciones con otros campos de conocimiento, incluso, con otros cursos del mismo programa, y así es menos probable que en esos la investigación sea utilizada como camino para conocer. A este respecto es vital llamar la atención sobre la asimilación que se hace de la investigación con la consulta bibliográfica a profundidad.

- La investigación como solución propedéutica: en la medida en que directores de programa y 
profesores le asignan a la investigación propósitos de formación relacionados con la potenciación de la capacidad de escritura y argumentación; como si entonces se investigara para aprender a escribir y argumentar, y no al contrario, escribir y argumentar para hacer investigación, como podría pensarse desprevenidamente.

Estas dos últimas concepciones de la investigación no son exclusivas del ámbito nacional. La revisión de algunas experiencias internacionales deja ver la alusión a experiencias didácticas orientadas al desarrollo de habilidades para la investigación, cuyo énfasis a pesar de algunos casos aislados, se ha dirigido más a pensar el mejoramiento de las prácticas docentes, tendientes al desarrollo de un pensamiento profundo y crítico en las áreas, que a fortalecer la investigación de los estudiantes; de allí que no se enseña a investigar al estudiante, sino que se le enseña mediante la investigación. Trabajos como el de Seymore, Hunter, Laursen \& Deantoni (2004, citados por Jalbert, 2008), indican las ventajas para el aprendizaje que ofrecen los programas de investigación en pregrado, así: aumento del interés de los estudiantes en la disciplina, aumento de la preparación profesional y de las habilidades, claridad en las metas de formación profesional, mejora el pensamiento crítico y la comprensión del proceso de investigación, aumento de la auto-confianza en la capacidad de hacer investigación y inserción en comunidades de aprendizaje.

Por su parte Lopatto (2004, citado por Jalbert, 2008) identificó los siguientes beneficios: fortalecimiento de la expresión oral y escrita y del trabajo autónomo, aprendizaje de una conducta ética, incremento en la capacidad de tolerancia a los obstáculos y mejora en la capacidad de análisis de datos.

\subsection{La promesa y la acción en los cursos de formación para la investigación: la lectura de los profesores}

La lectura de los profesores se hizo con base en dos instancias: i) el análisis de las cartas descriptivas de los cursos de investigación que ellos orientan y que fueron aportadas al estudio, por considerar que éstas contienen las directrices institucionales y del programa; y ii) las narrativas construidas a partir de los grupos focales, identificando alusiones de los participantes de acuerdo con la siguiente categorización: el para qué de la formación para la investigación, el cómo de esa formación y el qué (contenidos) de la misma.

\subsubsection{Sobre las propuestas microcurriculares}

En términos de lo observado en las cartas descriptivas que contienen las propuestas microcurriculares de los cursos de investigación, o sea lo prometido en los cursos, podría plantearse las siguientes inferencias generales ${ }^{5}$.

Entre los distintos programas, la fundamentación formativa de las cursos teóricos y otros (que ya fueron identificados en el apartado anterior) coinciden en la necesidad de transformar al sujeto, sobre la base del vínculo consustancial entre lo epistemológico, lo teórico y lo humano; todo mediado por la comprensión histórica de los objetos de estudio de este tipo de cursos. De acuerdo con Klafki (1988), esta es una utilización crítica de contenidos que no necesariamente son críticos, pues no por ser teóricos comportan esa característica. Es claro que los cursos de epistemología y pensamiento contable favorecen tal propósito, por ser muy propicias para ejercer "la capacidad de crítica y de juicio, la capacidad para la reflexión sobre relaciones de poder y de intereses sociales y sus condiciones, aprendizaje del aprendizaje y cosas semejantes" (Klafki, 1988, 101). La discusión de fondo, radica en pensar de qué manera la metódica, como formas de organización de la enseñanza para alcanzar tales fines, contribuye al propósito de formación, asunto que pareciera ser difícil de decidir.

Desde el punto de vista de los cursos de formación metodológica y de práctica investigativa o aplicación de la investigación, puede inferirse que el énfasis metodológico de éstos disipa la idea de formación

5 Pistas generales, dado que el análisis minucioso de las propuestas microcurriculares es objeto de otro artículo, debido al espacio que requiere esa descripción y discusión, a la luz de la propuesta que Klafki hace para ello. 
del sujeto; pues, en algunos programas no aparece y en los otros se refiere a una dimensión cognitiva -especialmente preocupada por la apropiación de la metodología y operatividad de la investigación- que probablemente invisibiliza al sujeto histórico y social. El contexto en el cual este sujeto se desenvuelve es el de una sociedad que produce, reproduce y acumula conocimiento, y esta lógica se hace presente en las declaraciones sobre los productos requeridos en el curso; así, los principios de racionalidad, sistematicidad, cooperación y comunicación se convierten en los ejes de formación. En últimas, en estas propuestas microcurriculares no se hacen visibles los argumentos que propongan condiciones de transformación social y personal, en el sentido de la reflexión por la condición humana; la mayor alusión a la formación para el futuro radica en la posibilidad de formar a quienes llegarán a hacer parte de las comunidades académicas, como un ritual de paso que "permite entrar a un mundo reservado a pocos" (Carlino, 2005, 25).

Es posible suponer que por ser áreas de formación metodológica, los propósitos de formación crítica se diluyan. Empero, es necesario enfatizar que los métodos se relacionan directamente con unas concepciones epistémicas vinculadas con concepciones acerca del mundo, la sociedad y el sujeto; por lo tanto, no es viable pensar el método en ausencia de esas reflexiones. Además, es posible darles ese carácter mediante dos posibilidades: integrándolos con contenidos críticos, o aplicando una metódica que conscientemente potencie las posibilidades de interacción social, capacidad de autogestión, actitud crítica y solidaridad, ambas expresadas por Klafki (1988) como las posibilidades formativas de la metódica.

\subsubsection{Sobre las experiencias de los profesores}

En la perspectiva experiencial de los profesores, narrada en los espacios de grupos focales, se discuten las intencionalidades formativas, las estrategias para lograrlas y los contenidos abordados. En términos de las intencionalidades formativas de los distintos cursos de investigación puede identificarse la preocupación por dos sujetos: el estudiante y el profesor quién más que como sujeto, aparece como portavoz de la disciplina.

\section{- Las intencionalidades formativas: el Para qué}

El estudiante como sujeto de la formación: En las manifestaciones de los profesores puede inferirse que la investigación representa potencialidades para la formación, en tres sentidos: su subjetividad, su desempeño académico y profesional, y sus actuaciones en el ámbito social. En primera instancia, para algunos profesores la investigación como camino hacia la apropiación y producción de conocimiento, provoca estadios de felicidad, porque esto les permite a los estudiantes ampliar su comprensión del mundo y hallarle sentido a la carrera profesional por la que han optado. De ahí pareciera derivarse que la dimensión subjetiva del estudiante se ve enriquecida en la medida en que se sienta satisfecho con sus horizontes de actuación profesional. Desde la óptica de los profesores, el mayor sentido de realización se otorga a partir de la sintonía con esos ideales:

"Trato de interpretar a través de algunas conversaciones con estudiantes lo que para ellos podría significar los aspectos positivos de ver materias como seminario de investigación $u$ otras materias afines, en concreto considero que este tipo de materias encuentra bastante resistencia en principio por parte de los estudiantes y los pocos que tal vez otorguen un sentido positivo a estas materias, identifico en ese sentido positivo una mayor identidad con aspectos disciplinares o con otros aspectos disciplinares más allá del inmediato ejercicio profesional. Ejemplo, alguna vez una estudiante me decía: "profesor yo no sé qué hubiera sido de mí, si usted en algún momento no me hubiera hablado de la historia de la contabilidad", porque dada las características de ella y sus gustos académicos, como que no se imaginaba en el ámbito de la empresa y entonces encontró una mayor identidad o digámosle una mayor felicidad si se quiere, como individuo, a partir de la visualización de los contenidos disciplinares" [Profesor participante en grupo focal].

No obstante, estos momentos de iluminación son más bien escasos, ya que la generalidad expresada 
es la del desencanto y la angustia por no lograr concitar en el estudiante esa pasión que la investigación despierta en el profesor, en tanto las conexiones que se alcanzan no trascienden sino "para aquellos que buscan la felicidad" [Profesor participante grupo focal].

"Yo tengo estudiantes en seminario de investigación I, que fueron capaces de formular esa pregunta, que cosa tan bacana los chinos emocionados; llegaron al segundo nivel: -¿cuál es el problema? -jumm. No profe, eso era del semestre pasado. -Sí, pero la idea de llevar un proceso, ¿qué hubo de las expectativas que usted tenía?, ¿qué hubo de esas ansias que usted había manifestado por el problema, ese interés, de esa cosa que yo vi tan interesante el semestre pasado?" [Profesor participante grupo focal].

Tal desencanto surge, de acuerdo con otras explicaciones, de la pérdida del sentido social por parte de los propios profesores, al ser incorporadas en la dinámica institucionalizada de la investigación; como si al incluir la investigación en el contexto universitario, ésta se hubiera domesticado:

"Había personas, habían comunidades que tenían un proyecto más allá del laborismo dentro de la empresa por parte de los contadores, de la elaboración de estados financieros, había escenarios donde se preguntaban sobre el papel político que nosotros teníamos sobre el proyecto histórico de la contaduría pública, sobre el problema de la representación de la riqueza, de la reproducción de la riqueza y de la distribución de la riqueza como aspectos que determinan la vida de las organizaciones y el equilibrio social; ese tipo de reflexiones se daban en ese tipo de escenarios, que no se están dando ahora cuando la institucionalidad absorbe estos cuadros, como que ya nos echamos a descansar y resulta que dentro de la institucionalidad uno encuentra docentes que consideran la contaduría pública como un proyecto de vida, como un proyecto de darle sentido a su existencia" [Profesor participante grupo focal].

Sobre el segundo sentido, el desempeño académico y profesional, los profesores afirman que la investigación favorece los desempeños del estudiante y futuro contador público también en tres aspectos: el enriquecimiento profesional para la escritura y la crítica, la ampliación de las perspectivas interdisciplinares y la introducción en la cultura académica. El primero de éstos se logra esencialmente con el acercamiento a las perspectivas teóricas y epistemológicas y la construcción de anteproyecto y proyecto de investigación, lo cual en algunos casos se expresa en un desempeño profesional enriquecido, menos rutinario y mecánico que aporta niveles de competitividad diferentes en el ámbito del desempeño laboral. Tal y como se observa en la siguiente mención que un profesor hace de lo afirmado por un estudiante:

“(...) vea profe, lo que pasa es que yo estoy con otro compañero que también se supone del mismo nivel mío, pero él no es capaz de hacer este tipo de redacciones porque a él no le enseñaron, y me pregunta entonces ¿es que a usted le enseñaron a redactar? (...)" [Profesor participante en grupo focal].

Este detalle puntual se expresa en términos más generales al describir la apertura de horizontes como resultado de la formación investigativa, la cual libera al contador de la carga rutinaria que históricamente se le ha endilgado:

"Nuestra Universidad no pretende que haya 500 investigadores de aquí a 5 años, pretende que por lo menos haya unos contadores públicos capaces de cuestionar su ejercicio profesional y de ejercerlo lo más ampliamente posible, que no sean simplemente el contador de escritorio y que después de 30 años si es que todavía puede, se pensiona en la misma empresa y que lo único que hizo fue registrar y por eso nunca movió el escritorio del lado de la ventana para poder saber dónde quedaba lo que podía ver" [Profesor participante de grupo focal]. 
Eso que se puede ver se declara como resultado del segundo aspecto, la mencionada ampliación de las perspectivas interdisciplinares, entendidas como el diálogo con otras disciplinas y sujetos provenientes de estas, intenciones que son coherentes con las demandas de la sociedad del conocimiento, que se preocupa esencialmente por la interacción de los campos de conocimiento y las comunidades académicas.

"Entonces con ellos se ha evidenciado que cada uno pone en el escenario del afuera frente a las áreas de las ciencias administrativas una problemática, y cómo la interpreta el negociador, el administrador, entonces eso va generando no solo esos espacios de reflexión, sino esas hermenéuticas de también el escenario de la transdisciplinariedad de escuchar al otro qué piensa frente a un fenómeno que puede ser que yo consideraba muy de mi área y el otro también como lo piensa" [Profesor participante grupo focal].

O con una nueva manera de acercarse al contexto, de entenderse en relación con el mundo. y sobre todo de entender la escritura como el testimonio de una mirada propia que se ha ido construyendo:

\begin{abstract}
"Entonces a mí me gusta trabajar siempre como con muchas referencias al contexto, tratando de hacer que la investigación sea más usada como herramienta para aproximarse al contexto, que no sea en sí como una finalidad[...] ]así sea que en el semestre escribamos dos páginas, pero son dos páginas de él y que lo pusimos a hacer alguna reflexión. Entonces creo que esa es una fortaleza que he tratado de cultivar, que el muchacho se apropie del proceso investigativo como una mediación para él, para su propio aprendizaje y no simplemente pues un ritual académico más de cumplir" [Profesor participante grupo focal].
\end{abstract}

El tercer aspecto, la introducción en la cultura académica, se caracteriza por el manejo propio de su lenguaje, la capacidad para apropiar conceptos y perspectivas teóricas, la facilidad para la escritura de documentos académicos, la habilidad para diseñar y utilizar métodos no sólo para la investigación sino en general para cualquier actividad del trabajo, entre otros.
“(...) es lo que llamaría la tradición escrita, la necesidad de utilizar los instrumentos de la investigación permanentemente para ir documentando la experiencia investigativa, generalmente uno les enseña las llamadas fichas de trabajo o los diarios de campo y mediante estos instrumentos ellos se van apropiando de un elemento de la cultura académica que es siempre escribir lo que se hace, lo que se reflexiona; ese es un elemento [de la cultura académica] supre- mamente importante dentro de lo que es la experiencia de la metodología de la investi- gación" [Profesor participante grupo focal].

De esta forma, se piensa que el sentido se logra en tanto el estudiante pueda acceder a esa cultura, pueda sentirse parte de esa interacción simbólica que articula elementos epistemológicos, teóricos, y metodológicos.

“(...) Cuando uno introduce en la posibilidad de la investigación a un estudiante, ellos rompen esa barrera, rompen ese caparazón y se dan cuenta que esa estrategia va a la práctica. Hay unos elementos filosóficos y otros elementos políticos, sociológicos que desafían el mundo e indudablemente la experiencia en investigación, enseñar la metodología, amplía los horizontes de los contadores" [Profesor participante grupo focal].

En el tercer sentido, las actuaciones del estudiante en el ámbito social y organizacional, los profesores plantean que el trabajo en equipo es quizá el aprendizaje más importante para el que prepara la formación investigativa, y a este los profesores le asignan dos responsabilidades: uno, formar a los estudiantes para la interacción social en términos de su habilidad para superar los desacuerdos, y dos, favorecer la configuración de relaciones de cooperación y solidaridad entre los estudiantes, de modo que sea factible la discusión, apropiación y construcción de 
conocimiento con sus pares de la misma y otras disciplinas. "Se rescata mucho la necesidad de trabajar conjuntamente, de hacer las cosas y de entenderse y de superar los desacuerdos y de buscar los espacios de tiempo y esas cosas" [Profesor participante focal].

Dicha construcción se orienta más a la capacidad de producir conocimiento útil para la empresa, que a la posibilidad de rescatar el conocimiento emanado de la realidad social.

"El trabajo en equipo es una gran fortaleza, indudablemente, y la reflexión de pensarse que ellos hacen investigación de manera cotidiana, pero de manera distinta, no tan rigurosa como lo vemos en la academia, pero que en las organizaciones también se da" [Profesor participante grupo focal].

De los anteriores aspectos, llaman la atención dos elementos: de un lado, la posible asimilación de la crítica a la cultura académica, pues en la primera se resalta la capacidad de apropiación teórica, más que a la actitud de vigilia y sospecha frente al devenir social, económico y cultural del entorno; además de la connotación de la crítica como esperanza de una actitud futura del profesional. Por el otro lado, la alusión al ámbito social, en dos perspectivas que inicialmente podrían parecer distintas, pero que en una lectura más detenida, pueden estar refiriéndose a lo mismo: lo social desde el punto de vista de la cooperación y redes de solidaridad, y lo social como sociedad del conocimiento. De la descripción que se hizo en los párrafos anteriores de estos aspectos, puede notarse que ambos sentidos aluden en últimas a la perspectiva de trabajo mancomunado entre las disciplinas y las comunidades académicas, y menos a la de las relaciones sociales que son impactadas, determinadas o ignoradas por la representación que hace la contabilidad y el ejercicio profesional.

\section{- El profesor como sujeto portavoz de la disciplina}

La consideración del profesor también como sujeto de la formación para la investigación, proviene de advertir que en las declaraciones de los profesores, los estudiantes y la disciplina aparecen como naturales preocupaciones de la misma, pero no así el pro- fesor. Desde este punto de vista, el profesor investigador, no se evidencia claramente como sujeto de formación. Su importancia política, epistemológica y política se subordinan a la necesidad de transmitir el deseo y la pasión como condiciones vitales para que la formación para la investigación reporte logros por parte de los estudiantes, pero éstas no se consideran aspectos esenciales para que un profesor oriente los cursos de investigación; de hecho, esta consideración del deseo, parece imponerse por encima del requisito de tener experiencia en investigación contable.

"Yo creo que lo que han dicho los profesores de empezar uno pues jovencito en la investigación, es interesante para los estudiantes porque lo ven muy relacionado con lo que hablamos ahora del apasionamiento, cuando uno ve en la investigación uno habla con mucha pasión de lo que hace, por ejemplo desde los estudiante le empiezan a preguntar a uno que es lo que usted ha investigado, cierto, y le prestan atención a uno sobre eso" [Profesor participante grupo focal].

Desde esta percepción, la experiencia investigativa del profesor se convierte más en un asunto de interés, de motivación hacia el ejemplo, de legitimidad del rol docente, más que de conocimiento necesario para orientar a los estudiantes en los problemas y discusiones propias de la disciplina. De allí, que en gran medida la experiencia investigativa del profesor, contribuye esencialmente a solucionar aspectos metodológicos y técnicos, más que a orientar críticamente la comprensión del estudiante. La experiencia investigativa, le permite al profesor:

\section{“(...) poder hablar directamente con li- bertad al estudiante de los métodos, de las formas de buscar información, de cómo utilizar la información pues para que sea más factible y más cercana al estudiante" [Profesor participante grupo focal].}

De todos modos, es necesario reiterar que a pesar de este reconocimiento, se observa que la mayor parte de los profesores que orientan cursos de investigación contable, no hacen investigación contable. 
En algunos profesores que investigan, aparece la disciplina contable como preocupación fundante de la formación para la investigación; es decir, en esos casos pareciera que en el proceso formativo fuera más central la disciplina que el estudiante, y sobre todo más importante que las atribuciones valorativas del profesor acerca de lo social. En la medida en que se nombra que la investigación contable debe reportar resultados esencialmente en dos sentidos: en primer lugar, la ampliación de los horizontes teóricos, epistemológicos y metodológicos de la contabilidad; y en segundo lugar, con base en lo anterior, el mejoramiento de la imagen que la disciplina tiene en el ámbito universitario, académico e, incluso, social. Por supuesto, importa la formación de los estudiantes, pero en tanto ésta les sirva a ellos para que se comprometan, en sus ejercicios investigativos de aula, con la reflexión disciplinar, de modo que puedan tomar distancia de las miradas más instrumentales de la contabilidad.

\begin{abstract}
“(...) eso también permitiría que ellos vayan reconociendo, lo cual les parece a veces bastante sorprendente, que la contabilidad supere los límites de la técnica, los límites del ser prácticos y se trasciende hacia un nivel fundamentalmente que les sirve para descubrir la contabilidad como una disciplina académica, como una disciplina que con los conocimientos que va adquiriendo han sido productos de construcciones teóricas y de reflexiones epistemológicas, eso les parece sorprendente que por ejemplo la forma de hacer un registro contable tenga unos antecedentes en pensamiento de contabilidad" [Profesor participante grupo focal].
\end{abstract}

En algunos profesores esa pretensión se llena de sentido, hasta el punto de que se convierte en un factor cargado de emotividad y angustia, por no lograr convocar desde el deseo el gusto por la investigación, la cual no tiene la legitimación necesaria para imponerse.

"Yo no veo al profesor de tributaria emocionado con formarlos a todos como tributaristas y si hay alguien al que no le gusta, perdió la materia y no más, chao y repite; el que no aprendió contabilidad que repita el curso; en cambio para uno que alguien no le trabaje en investigación es angustioso, es una cosa de que -ese chino porque no (...) $y$ tiene cosas en el coco y es capaz de pensarlas, que le hace falta- $y$ ahí es cuando uno comienza a fustigarse ¿En qué estamos fallando? ¿Qué es lo que hace falta?" [Profesor participante grupo focal].

Derivado de estas pretensiones, la mayor expectativa de aquellos profesores es que los estudiantes se conviertan en investigadores de la contabilidad, concretamente en los asuntos teóricos de la misma, lo cual en alguna medida controvierte las intencionalidades formativas asignadas a la investigación, referidas a la configuración de la subjetividad.
“(...) identifico en ese sentido positivo una mayor identidad con aspectos disciplinares o con otros aspectos disciplinares más allá del inmediato ejercicio profesional, ejem- plo, alguna vez una estudiante me decía: "profesor yo no sé qué hubiera sido de mí, si usted en algún momento no me hubiera hablado de la historia de la contabilidad", porque dada las características de ella y sus gustos académicos, como que no se imagi- naba en el ámbito de la empresa y entonces encontró una mayor identidad o digámosle una mayor felicidad si se quiere, como in- dividuo, a partir de la visualización de los contenidos disciplinares" [Profesor partici- pante grupo focal].

El sujeto profesor aparece solo como mediador, como figura que establece un vínculo entre el sujeto y la disciplina. En esa relación emergen sentimientos de angustia, soledad, pasión. Una pasión que se contagia: se le pide pasión al estudiante, pero una pasión que emana de los profesores hacia ellos, como en un proceso de vaciamiento que resulta extraño, pues las pasiones son una construcción íntima. Una soledad que se evidencia en el profesor que se dedica especialmente a asignar calificaciones y 'llenar papeles', que no hace comunidad académica, que no se reúne a hablar de sus cosas, de su quehacer, de 
su angustia. Y una angustia que procede de saber la resistencia y el sinsentido que la investigación genera en los estudiantes.

\section{- Las estrategias metodológicas: el Cómo}

La crítica aparece en los cursos de investigación como intencionalidad formativa -como se mostró en el apartado anterior- tanto como estrategia metodológica, pues los profesores juzgan que el inicio del proceso investigativo es una revisión a la realidad de lo contable y las organizaciones, con una actitud crítica y reflexiva, de modo que puedan formularse proyectos que aborden temáticas pertinentes y necesarias para esos escenarios. De esta consideración se deriva que una forma de aplicar la crítica como metódica es la selección de los temas a abordar en los ejercicios investigativos; sin embargo, tanto profesores como coordinadores de investigación plantean que los temas más abordados por los estudiantes en sus proyectos actualmente están relacionados con la internacionalización contable, la valoración de recursos ambientales y el capital intelectual, la formalización de las pymes, asuntos tributarios, contabilidad o auditoría forense, procesos de control, entre otros; mientras que temáticas como el papel de la contabilidad en el capitalismo, la pobreza, los asuntos teóricos y epistemológicos de la contabilidad, la educación contable, la historia de la contabilidad, están ausentes. Pareciera haber una renuncia a aquellos temas que escapan al ámbito de la empresa.

\section{“(...) pero yo veo un imaginario muy fuerte en el estudiante; o sea, el estudiante parecie- ra que como profesional en el único lugar que se ve es en la empresa privada, el resto de la sociedad no existe, la contabilidad y la contaduría no existe en ningún otro espacio" [Profesor participante grupo focal].}

En este campo de las temáticas emerge nuevamente la angustia del profesor. Una angustia que nuevamente radica en la teoría más que en lo social, porque la atribución es cambiar el mundo por vía de la teoría.

"Yo recuerdo que al principio era un angustia muy tenaz que todos los trabajos fueran iguales o que a ellos no les gustara la teoría contable, entonces uno llegaba a un salón y si veía la gente por allá dispersa, uno decía soy un mal profesor, que pesar, no vamos a cambiar el mundo (...) después uno ya dice, «no es que no es así», es decir, en últimas no van a ser nuestras preocupaciones, porque no somos estudiantes típicos de la contaduría pública, o sea, nosotros no hacemos parte de los regulares en la formación contable" [Profesor participante grupo focal].

De esto emana el segundo aspecto del cómo: las formas de vincular el interés de los estudiantes. Los profesores manifiestan que la motivación de los estudiantes es uno de los caminos más importantes para lograr resultados visibles en la formación para la investigación, y se produce a partir de factores intrínsecos y extrínsecos. Los primeros son, en algunos casos, esencialmente la razón utilitaria de satisfacer un requisito para el grado, así como la voluntad de conocer, concretamente de ampliar los horizontes de su carrera profesional. Los segundos provienen específicamente de la posibilidad de vincular el conocimiento con las condiciones reales de los estudiantes.

"Es necesario profundizar más en investigación empírica, la investigación empírica creo que es el vínculo que puede conectar mi sentido con el sentido de finalidad del estudiante" [Profesor participante grupo focal].

La investigación básica se interpreta así como algo lejano al interés del estudiante, como algo que está por fuera de sus posibilidades y necesidades. Por tal razón, se expresa la necesidad de darle corporeidad a esa masa ideal de la teoría, mediante la contextualización, la cual, cómo ya se afirmó, se restringe el mundo de la empresa.

Estos factores extrínsecos también provienen específicamente de la empresa, en la medida en que se asume que la investigación produce un plus que puede ser ejercido en ese lugar, sin que la empresa misma lo exija como perfil de trabajo; en este sentido, los profesores valoran que las empresas de alguna manera se vinculan con los procesos investi- 
gativos de los estudiantes y les abre el espacio para que ésta misma se convierta en objeto de estudio de tales procesos.

\begin{abstract}
“(...) en el caso de nosotros desde que estamos haciendo el simposio, los más comprometidos indudablemente son los patrones de los muchachos y ellos han estado en los simposios escuchándoles las propuestas, lo que han reflexionado y hemos hecho muchas cartas contándoles en donde están, para donde van, cuales son las fechas $y$ ellos mismos los han acompañado, nosotros sentimos el hecho de comunicarnos y estar muy cercanos con la organización de los chicos, muy interesante" [Profesor participante grupo focal].
\end{abstract}

En otras palabras, la motivación intrínseca o extrínseca pareciera en todo caso enmarcarse en la dimensión del trabajo y en el escenario de la empresa, y desde la utilidad en este espacio se juzga el éxito y pertinencia de la formación investigativa.

En un sentido similar al anterior, aparece el deseo del estudiante en los cursos de investigación, un deseo que trasciende la idea de motivación y que se vincula con la posibilidad de que los estudiantes en los cursos de investigación le hallen sentido a su elección profesional, porque las miradas disciplinares les seduce como opción de trabajo, o porque los procesos de problematización de la realidad y de crítica a la misma les satisface y congracia como sujetos.

El deseo de los estudiantes es uno de los aspectos más problemáticos a juicio de los profesores, pues los cursos de investigación comúnmente son asumidos por los estudiantes como espacios 'de relleno' en los planes de estudio o como contenidos que pueden ser interesantes pero que no les genera valor para su desempeño profesional; en últimas, de acuerdo con la experiencia de los profesores, habrá resistencia en los estudiantes hasta que ellos le hallen sentido a la formación para la investigación; esto sumado a la dificultad que reconocen los profesores en los estu- diantes para leer documentos académicos, escribir en el lenguaje propio de la academia, pensar problemas de investigación relevantes para la contabilidad o la contaduría pública, entre otros. Así afirma un profesor al referirse al choque entre sus expectativas teóricas y las expectativas del estudiante: "Hay un vacío entre el sentido final que yo busco y el sentido final que busca el estudiante" [Profesor participante del grupo focal].

Resulta llamativo que los profesores manifiestan que la motivación y el deseo del estudiante operan como ritual de iniciación para los cursos de investigación, pues éstos siguen teniendo un peso marginal en los planes de estudio, lo cual genera que los tiempos para la investigación les resulte cortos a los estudiantes frente al alcance del trabajo, además de que ante una menor cantidad de créditos corresponde una menor cantidad de trabajo independiente de los estudiantes.

Con respecto a la metódica, hay dos procesos que son fundantes en la formación investigativa, y así mismo los valoran los profesores de investigación, como procesos muy sensibles en sus experiencias: el primero es el de problematización para la formulación de los proyectos en los ejercicios investigativos, y el segundo es el abordaje de la relación objetométodo. Es común a los profesores la consideración de que los estudiantes deben elegir los temas de su preferencia, para ser abordados como problemas de investigación, al punto de que en algunos casos no necesariamente tengan que ser del campo contable; ello, como requisito para que el estudiante en alguna medida goce el proceso, o al menos le genere menos resistencia.

En términos generales, los profesores invitan a esa problematización fundamentalmente por dos vías que podrían denominarse una de carácter vertical y la otra horizontal. Esta última, la más seguida por los profesores, corresponde justamente a esa manera de seleccionar los problemas de manera autónoma por parte del estudiante, a partir de sus preferencias temáticas ${ }^{6} \mathrm{o}$ las potencialidades halladas en otros cur-

6 En los cursos de formación metodológica, especialmente si se ubican en semestres tempranos, los temas no necesariamente tienen que ser contables u organizacionales. 
sos; en esta problematización el profesor cumple el papel de orientador conceptual del interés temático. En la vertical, los profesores proponen a los equipos de trabajo una temática para sus proyectos, bien sea por encontrarlo favorable para las potencialidades de los estudiantes, como estrategia para favorecer una discusión de todo el curso sobre un tema central, o como forma de fomentar la comunidad académica y el desarrollo de una línea de investigación, al proponer preguntas abiertas de proyectos de investigación ya terminados o con la senda de investigación que trabaja el profesor. Este tipo de problematización vertical es poco acogida por los profesores, por resultarles en alguna medida conductista con el estudiante y menos cautivadora del interés de ellos.

"Como agarro esto: primero los programas de contaduría pública, si uno empieza a revisar contenidos y alcances y motivaciones, todos me van a terminar diciendo que pretenden ser constructivistas, pero no son más que conductistas tras ese constructivismo, seguimos creyendo que debemos entregarle al estudiante lo que merece saber para que pueda ejercer y si somos en serio constructivistas el estudiantes debe ser capaz de vincularse al proceso, no de aprendizaje sino de formación" [Profesor participante grupo focal].

Resulta vital decir que, de acuerdo con la experiencia de los profesores, los procesos de problematización son los momentos de la investigación que más les cuesta a los estudiantes.

La problematización es una etapa que no se surte por una única vía y en un solo curso. En los programas en los que los cursos de formación metodológica se ubican en momentos tempranos del plan de estudios, la problematización se acerca a la ruta método/metodología - contextualización - problema, debido tal vez a que en las etapas iniciales del plan aún no se tienen suficientes elementos que permitan el planteamiento de preguntas y problemas más complejos y pertinentes para la disciplina; tales elementos serían: teóricos de la contabilidad y otras disciplinas, contextuales de las organizaciones y la formación profesional o incluso la experiencia labo- ral, y metodológicos de los distintos modelos y sistemas de información contable. En últimas, se parte de la formación metodológica para formular problemas quizá más elementales, que permitan aplicar la metodología de investigación; parece ésta una ruta de pensamiento de carácter teórico o hipotético-deductivo, no porque se parta de la teoría, sino porque se parte de una identificación de problemas supuestos sin la suficiente decantación de estado del arte y viabilidad práctica y disciplinar.

En las propuestas curriculares cuyos cursos de investigación se ubican en momentos superiores del plan de estudios, la problematización podría atender más a un pensamiento epistémico, que trasciende la teoría (Zemelman, 2001), cuya ruta es contextualización - método/metodología - problema, pues al contar ya en esa instancia con los elementos antes nombrados, se enriquece el abordaje de la realidad cercana al estudiante, habiéndola pasado por el tamiz del pensamiento contable, económico, histórico y social aportado en otros cursos.

En cualquiera de los casos, los procesos de problematización también tienen una profunda relación con la instancia de la crítica, como intencionalidad formativa o como estrategia metodológica; pues pareciera más común comprender el hecho mismo de problematizar en función concretamente del desarrollo disciplinar o empresarial, y menos de la realidad social o del mundo amplio de las organizaciones y sus relaciones estructurales.

El otro proceso sensible en los cursos de investigación es el abordaje del método en relación con el problema seleccionado. En buena parte de las experiencias compartidas en el estudio, suele asimilarse el método de investigación con el proceso de operacionalización metodológica $y$, paradójicamente, los profesores manifiestan que en este proceso los estudiantes presentan mayores dificultades en los diseños de investigación analíticos, en instancias como la operacionalización de variables y la problematización, como ya se dijo. Con frecuencia, en los cursos de formación metodológica el tema de los métodos es uno de los centrales, y es expuesto por el profesor para todos los equipos de trabajo; mientras que en los cursos de práctica investigativa, son los equipos 
de trabajo los que consultan el método pertinente para su problema. En el estudio no logró profundizarse con suficiencia en las formas con las que se discute en los cursos la relación de los métodos con los temas a abordar.

\section{- Los contenidos de la formación: el Qué}

Los contenidos abordados en los cursos de investigación y afines son bastante comunes. Concretamente en los cursos de formación metodológica se abordan temas como: el problema de investigación, la formulación de un anteproyecto con todas sus fases, la metodología (no tanto el método), referentes (conceptuales, teóricos, contextuales), técnicas para el trabajo de campo, tratamiento de la información, construcción de informe. No en todos los cursos se cumplen todas estas fases; los profesores manifiestan que por efectos del tiempo real del curso, se privilegia el proceso de problematización y referentes, y se soslayan los aspectos operativos del informe.

De otro lado estas coincidencias de los contenidos temáticos de los cursos, que en todo caso se acercan a los manuales de investigación ampliamente difundidos, lo que se tramita permanentemente en los cursos de investigación, bien sea de fundamentación, metodología o práctica, es la concepción misma de investigación.

En los planteamientos de los profesores se hallan al menos cuatro ideas sobre lo que asumen por investigación: la primera es la idea de que la investigación es una práctica académica, que sigue un método para abordar un problema de la realidad contable. Con algunos matices, algunos profesores le suman a esto la idea de que como práctica académica, la investigación es formal y rigurosa, que se produce en la universidad de espaldas a la realidad que es la empresa, y que se preocupa especialmente por los productos, en términos de indicadores como las publicaciones, la cantidad de proyectos terminados, semilleros de investigación, convenios interinstitucionales, etcétera.

"La investigación en contaduría no nació en la universidad, nació de todos los estudiantes (...) Yo siento que cuando llega de esa forma como tan artificial la investigación a la universidad, entonces está el afán de que hay que insertar eso en los currículos, de que hay que hacerlo porque es un indicador más y todo eso (...) como no se había hecho nada de investigación o muy poquito, en lo que llevaba una carrera que fue reconocida hasta los 80', nos preguntamos ¿Qué hacemos? Pues hagamos lo que hace todo el mundo, y se empezó a construir como una mirada de la investigación desde esa óptica tradicional, de enseñar investigación a partir de la lógica de los proyectos de investigación" [Profesor participante grupo focal].

La segunda idea, asida por algunos profesores, es que la investigación es una actividad que debe permitir resolver problemas de las organizaciones, concretamente las empresas, porque ese es el escenario natural de emergencia de lo contable $\mathrm{y}$, por tanto, es allí donde debe aportar la investigación contable soluciones a los problemas cotidianos de tales escenarios. Como resultado de esta idea, la investigación suele asimilársele a una actividad consultora, en la que los estudiantes acuden a una empresa para proponer soluciones a un problema manifiesto con alguna instancia de sus sistemas de información contable o de control.

La tercera, la idea de que la investigación es una actividad que los seres humanos hacen permanentemente en la vida cotidiana, que siempre que el estudiante quiera conocer algo en profundidad y lo reflexione y busque en la literatura existente, él estará haciendo investigación. De esto se colige que las preguntas y reflexiones que los estudiantes hacen sobre su vida personal y social, así como sobre el mundo de las empresas y sus experiencias en éstas, son procesos de investigación, lo cual se suma a la consideración -presente en las manifestaciones de la mayoría de los profesores- de que el mundo real es el mundo de la praxis profesional, o sea, el mundo de las empresas, porque ese pareciera ser, dentro del amplio escenario de las organizaciones, el escenario natural de la contaduría pública. Este último aspecto, la asimilación de la empresa con el mundo real, se vincula estrechamente con lo que se entiende por 
teoría, pues para algunos profesores la teoría también es una construcción ficticia que hacen las comunidades académicas y que poco habla de la realidad.

"Ahora como se lo llevo al muchacho, como hago al muchacho, entonces vuelvo a lo que les dije al inicio, para mi si yo llevo la práctica y yo contextualizo al muchacho y le digo "es que usted esto lo hace realmente en la empresa" el muchacho va viendo de pronto o se va motivando un poquitico que hay que salirse de esos parámetros de lo ideal y que hay que tratar de aterrizar un poquito" [Profesor participante grupo focal].

Finalmente, la idea de que la investigación es una estrategia didáctica, útil para el aprendizaje de diversas materias. Sobre este asunto ya se presentaron algunas ideas en apartados anteriores aludiendo a la investigación como didáctica.

De este contenido resulta necesario advertir que, si a la investigación se le asignan intencionalidades formativas relacionadas con la configuración de la subjetividad -tal como se discutió en apartados anteriores-, habría que hallar en estos contenidos los que se piensan en función de tales propósitos, o comprender la manera en que éstos se satisfacen por medio de contenidos de carácter disciplinar. De acuerdo con Klafki (1986), los contenidos formativos se dirigen tanto a objetos de conocimiento disciplinares, como al aprendizaje social; la metódica y el contenido deben garantizar que el estudiante fortalezca el aprendizaje social, dado que es posible lograr el conocimiento de los objetos sin lograr aprendizajes sociales como: cooperación, solidaridad, debate argumentado e, incluso, la conciencia sobre la necesidad de transformación social, que justamente son nombrados como propósitos de los cursos de investigación. Klafki (1986) plantea que incluso puede lograrse aprendizajes objetuales por medio de metódicas inicialmente loables como el trabajo en equipo, pero generar consecuencias negativas, tales como crecer en el aprendizaje sobre la base del aprovechamiento de los demás.

\subsection{La comprensión de la formación para la investigación: construcción interpretativa}

La construcción interpretativa realizada a partir de la descripción anterior alude a tres grandes aspectos:

\subsubsection{Discusión sobre la presencia de lo socio-humanístico}

La forma en que aparece lo social y lo humano tanto en las intencionalidades formativas, como en las metódicas y los contenidos, deja ver en primera instancia que la relación de la contabilidad con esas dimensiones de la vida, especialmente con lo social, es naturalizada, se asume como dada por la obvia presencia de la contabilidad y la contaduría pública en una sociedad; pero no se discute ni amplia ni profunda ni técnicamente la forma en que la contabilidad determina relaciones sociales, y tampoco la manera en que las estructuras sociales reproducen su lógica en la contabilidad. Esta naturalización corresponde a la asimilación de lo social, con sus características y devenires, como un orden natural (Lechner, 2002), frente al que la contabilidad nada tiene que hacer.

Lechner (2002) arguye que de esta naturalización se deriva una des-subjetivación de la reflexión científica, pues si lo social es natural entonces no es determinado por criterios morales ni éticos conscientes, sino por leyes naturales del sistema abstracto de la sociedad, de modo que las preocupaciones por el bienestar humano en las organizaciones y como consecuencia de éstas, la transformación de las condiciones de inequidad y corrupción en lo privado y lo público, los ejercicios de poder que se tramitan en la representación contable, entre otros asuntos (Muñoz \& Sarmiento, 2010), no tienen porqué resolverse en la educación contable, pues corresponden a una mirada política, o sea de construcción deliberada, innecesaria ante el curso natural del mundo.

En la formación contable no sólo se naturaliza lo social, sino también la empresa. Tal como ya se nombró en la discusión metódica de apartados anteriores, la empresa se asume como el escenario casi único y natural de aparición de lo contable y, por tanto, del contador público; no pareciera haber in- 
terés por el amplio mundo de las organizaciones, y más bien se naturaliza que la contabilidad es para la empresa y que ésta también comporta unas lógicas frente a las cuales lo contable solo aporta sistemas de información, pero no determina ni transforma. Esta naturalización de la empresa como único escenario posible de desempeño profesional, equivale a considerar que ésta representa el ámbito social del contador público.

De este modo, lo social como escenario y fenómeno vinculante del sujeto se totaliza en el trabajo, el cual se convierte en la expresión del mundo de la vida, de lo cotidiano en el estudiante. Podría pensarse que la academia actúa como un agente mediador entre el mundo del trabajo y la vida cotidiana de los estudiantes; pero ésta se ocupa más de ofrecer respuestas a los problemas del mundo empresarial, en tanto es el medio que las exige, sin estímulo al pensamiento que dé respuestas a los problemas de lo cotidiano o lo que escape al mundo del trabajo, por cuanto sus preguntas específicas no son visibles a los ojos de lo académico. Quizá esto resulta coherente con el ethos de las sociedades actuales, que privilegia las respuestas dadas desde la teoría (Zemelman, 2001) y reduce el mundo de la vida al mundo de las cosas, en el que domina la razón instrumental que va esencializando al sujeto como un laborante, un hacedor de cosas (Arendt, 1993), una subjetividad productora (Martínez, 2010).

Además de estas naturalizaciones, pareciera que en las propuestas y desarrollos de los cursos de investigación hay una tensión entre al menos dos miradas sobre lo social: en una primera mirada, hay una preocupación por lo social como conjunto de relaciones $y$ de intereses que se tramitan y construyen en diversos escenarios, desde el educativo que vivencian los estudiantes (como el aula y el trabajo académico con pares, con las limitaciones que su tratamiento didáctico pueda tener), hasta el organizacional en el que laborarán y el de las múltiples relaciones por las que transitan; escenarios en los que se vive siempre con otros de otras partes y otros tiempos (Arendt, 1993), para cuya interacción se espera que la educación prepare dando los elementos para la construcción de acuerdos morales y éticos y, esencialmente, para la felicidad (Cortina, 1986).
La segunda mirada sobre lo social está relacionada con el afán de aparición en los medios de la academia y de participación en la sociedad del conocimiento, mediante la incursión en la cultura académica antes nombrada. Esta pretensión se impone no sólo en las intencionalidades formativas, sino esencialmente en la exigencia dispositivos metódicos (Vargas, 2011) tales como la comunicación del saber por vía de los artículos publicables, la interdisciplinariedad limitada al trabajo en equipo con pares de otras disciplinas, la restricción de lo cultural al campo de la cultura académica por vía del lenguaje especializado y el dominio de la teoría.

Habría que preguntarse entonces si lo cotidiano, lo que afecta y modifica la experiencia individual, y también lo social, lo que determina la vivencia de los grupos sociales de pertenencia, tuvieran presencia en la academia, el sujeto crítico de la educación contable no aparecería solo como promesa de un profesional humanizado, como postergación de una crítica ilustrada para el trabajo, sino que quizá estaría presente en eso que lo toca y moviliza en su presente.

\subsubsection{Discusión sobre el papel del profesor}

En los diversos enfoques de la educación, el papel del maestro es diferente; en algunas miradas contemporáneas, al tiempo que se valora y fomenta la responsabilidad y autonomía del estudiante para diseñar su proceso formativo, se desestima el papel también central del profesor. Pero también ahora hay modelos pedagógicos y didácticos centrados en el papel del profesor, que le exigen ser profundo conocedor de los procesos de aprendizaje específicos del campo que enseña (Tamayo et al., 2010, 47).

Desde ahí, el papel del profesor está pensado como orientador y compañero de las múltiples posibilidades de aprendizaje, como potenciador de la autodeterminación del estudiante, como el responsable del diseño de los ambientes educativos -para lo cual requiere ser conocedor de los estudiantes y sus formas de aprender- (Tamayo, 2003), pero la omisión de este rol lo confina a ser un supervisor de los avances de los estudiantes. No es el objetivo de este documento discutir las bondades y deficiencias de 
los diferentes roles asignados a los profesores, en las distintas perspectivas de enseñanza-aprendizaje, para eso resulta mejor consultar sistematizaciones amplias al respecto como la de Flórez (1994) y De Zubiría (2006). Conviene más bien discutir el papel que los profesores asumen en los procesos de formación para la investigación contable.

El primer rol que pareciera cumplir el profesor es el de motivador. En consideración de que la formación para la investigación, por múltiples situaciones, genera resistencia en los estudiantes, el profesor está encargado en primera instancia de hacer surgir su interés, mediante promesas sobre la utilidad de dicha formación en el futuro; un proceso de seducción que se asimila al de una esposa conocedora de la existencia de la amante. Aquí la amante representa a los demás componentes de formación, los cuales resultan más llamativos para los estudiantes, en tanto son los requeridos por el mercado laboral. Este tipo de relación pretende mantener viva la llama del gusto en el interior del aula de clase y aleja al estudiante de su realidad inmediata. Tal perspectiva es denominada por McLaren (2005, citado por Bruschtein, 2010) como la "pedagogía del deseo", una pedagogía en la cual el profesor transfiere al estudiante su deseo de rebelarse frente a las normas de la vida diaria, a espaldas de las condiciones de explotación de los estudiantes; es una educación pos-clasista en la cual prima el deseo del profesor, sin confrontar las condiciones de miseria del otro, las cuales le dan posibilidad de tener prosperidad en la pedagogía del deseo. El objetivo de esta pedagogía es, mediante la seducción, liberar al estudiante del estrés que sienten como producto de las dificultades económicas y condiciones de exclusión de su vida diaria.

El segundo rol es el de experto, quien tiene la responsabilidad de dirigir las principales metódicas de los cursos:

- La problematización, que, como ya se dijo, se produce por dos vías, una horizontal y otra vertical. La primera, aunque sea más un ejercicio de 'libertad' del estudiante, no está exenta de la ideología proveniente del entorno o incluso del profesor mismo, la cual delinea el mundo actual, con la lógica de la vida para el trabajo, el consumismo y la utilidad. La vía vertical, al provenir del profesor o de la institución, tampoco es ajena a esta ideologización, pues el currículo del programa también encarna las ideologías del contexto y la época. Es por esto que la problematización de la realidad no es una actividad crítica en esencia; de modo que el papel aquí del profesor consiste en mostrar posibilidades y dar elementos para que los estudiantes mismos opten por sendas de pensamiento, conocimiento y acción, como movimientos de autodeterminación, como lo plantea Klafki (1986).

McLaren (2005, 205) evidencia esta disociación al argumentar desde Giroux la forma como los micro-objetivos del aula, se separan de los macro-objetivos de la teoría. Estos últimos remiten a la posibilidad de que los estudiantes descubran las conexiones entre los propósitos de la educación que reciben y las reglas, los valores y las relaciones en la estructura social.

La escritura, que como también se expuso, es una de las intencionalidades formativas más comunes en la formación para la investigación, es por supuesto también uno de los dispositivos metódicos más importantes. Se reconoce que casi todas las etapas y estrategias de la investigación implican la escritura; pero al tiempo se reconoce que hoy por hoy los estudiantes universitarios llegan a la educación superior con serias dificultades al respecto, por lo que la investigación resulta ser una vía para potenciarla. Así el profesor, más allá de problematizar las creencias e ideologías de los estudiantes, resulta ser el experto que enseña las reglas básicas de la gramática y las estructuras complejas de la escritura como expresión -no tanto como producción- de pensamiento.

Al respecto, Carlino (2004b) es reiterativa en la necesidad de garantizar que los estudiantes al escribir acudan a la opinión de pares y al acompañamiento del profesor, pero no desde la mirada calificadora de la tarea cumplida, sino desde el rol de un lector que se enfrenta a un texto con unas necesidades específicas y unas situaciones de contexto, lejanas de las del estudiante escritor. 
Agrega que la escritura tiene un enorme poder epistémico al favorecer la constante revisión de lo que se sabe, como resultado del "conflicto que enfrenta el escritor entre las limitaciones del propio saber y la necesidad de lograr un texto eficaz" (Scardamalia \& Bereiter, citados por Carlino, 2004a, 323). Sobre todo que es necesario reconocer la diferencia que existe entre la escritura privada en investigación que ocurre en el contexto del descubrimiento y la escritura pública relacionada con la manera como este conocimiento se justifica ante una comunidad (Carlino, 2005). Si bien la escritura pública oculta las dudas y retrocesos propios del proceso, la escritura privada se hace con el fin de organizar el pensamiento y la labor del docente debe orientarse a estimular y compartir esas reflexiones provisionales.

- La evaluación es cada vez más reconocida en la literatura académica como una de las instancias formativas más sensibles y potentes. En perspectiva, se esperaría que la evaluación en los procesos de formación investigativa resultara como un espacio deliberativo, de confrontación de argumentos y perspectivas científicas y políticas, y esencialmente de construcción de acuerdos incluso sobre la base de disensos. Contrariamente, suelen resultar como una instancia obligatoria y resignada, en la que se valora al menos el cumplimiento de los tiempos, la valiente asistencia a las tediosas clases de investigación, el manejo de las normas de referenciación, y la denodada preocupación por una de las modas del campo contable; aspectos todos referidos a aprendizajes técnicos necesarios para sobrevivir en la universidad y tal vez incursionar en la sociedad del conocimiento, pero no se avizoran instancias evaluativas formadoras de los logros en la subjetividad. En pocas palabras, se pretenden transformaciones del sujeto, pero se evalúan las capacidades del trabajador.

- Reducción de la metódica a la enseñanza del método: como previamente se conceptualizó, la didáctica en sentido general comporta como una de sus decisiones, no la única, la reflexión acerca de las potencialidades formativas de la metódica. Esto es, la discusión sobre la manera como las mediaciones del profesor pueden contribuir o no a la formación. Según Klafki (1986) tales decisiones pasan por pensar la metódica inherente a los procesos de constitución histórica de los contenidos, esto es, a los métodos propios de ese saber; pero también derivan en la discusión sobre las implicaciones formativas de asumir tal método y sobre las posibilidades de aprendizaje del mismo. Esto implica una tarea de pensar las exigencias de acceso a esos contenidos en presencia de unos condicionantes culturales y formativos. De allí, que el asunto de la metódica no puede resolverse con la presentación declarativa de unos métodos, los cuales se explican como conocimientos cerrados en sí mismos, para proceder a transferir su aplicación en diferentes contextos, deviniendo en inevitables actitudes instrumentales.

De esto se deriva la necesidad de consolidar la investigación educativa como un campo de investigación independiente que dé cuenta de aspectos vitales en la enseñanza de la contabilidad. Asuntos como, por ejemplo, el impacto de las diferencias disciplinares en el aprendizaje de los estudiantes, merecen mayor atención; razón por la cual, en cualquier área del conocimiento, las discusiones sobre las condiciones de enseñanza y aprendizaje de la disciplina deben tener su propio campo de discusión (St. Pierre et al., 2009, 127).

Tales argumentos se complementan con la importancia que tiene el educador contable para una formación que respete las bases conceptuales, la adecuación procedimental y el contenido técnico; lo cual adquiere mayor importancia en tanto la contabilidad, en alguna medida, se asume como un lenguaje universal, de una importancia alta no solo en el mundo empresarial sino también donde no prima el ánimo de lucro (St. Pierre et al., 2009, 127). Esto sumado al entorno cambiante propio del contexto que demanda un educador adecuadamente preparado para enfrentar el cambio.

Las anteriores consideraciones derivan en impactos formativos, que más allá de lo espe- 
cíficamente cognitivo, inciden en lo ético. Los dramáticos casos de corrupción, han mostrado como la inadecuada formación de los educadores contables, suman en la simiente de muchos casos de inmoralidad ampliamente difundidos (St. Pierre et al., 2009, 127). De allí que el vínculo formativo que emprende la educación está asociado a los fundamentos éticos y sociales de la profesión del contador; lo cual ofrece muchas posibilidades de investigación tanto teóricas como prácticas. Lo anterior crea la demanda de una enseñanza más efectiva, que parta de la crítica a la obsesión investigativa de las principales universidades protagonistas de la sociedad del conocimiento, obsesión que ha ido en detrimento de la calidad de la enseñanza en los pregrados (St. Pierre et al., 2009, 127).

- Queda por nombrar el tercer rol del profesor: el de asesor y modelo. El rol de asesor es común en los cursos de formación metodológica $y$, especialmente, en los cursos de práctica investigativa; las asesorías se conciben como espacios de control del cumplimiento de las tareas por parte del estudiante, de evaluación de sus avances con respecto a los objetivos trazados, o de acompañamiento didáctico. En este rol debe resaltarse que no en todos ni la mayoría de los casos, los profesores que enseñan investigación son al tiempo investigadores, y como suele ocurrir en muchos campos, los investigadores que enseñan investigación tampoco son profesores formados para ello; en los pocos casos en los que profesores son al tiempo investigadores, ellos desempeñan un rol de modelo para sus estudiantes, de ejemplo del que tomar o desechar prácticas. Por tal razón, surge la necesidad de convertir la experiencia investigativa en didáctica para la formación, y nutrir la formación didáctica con experiencia en hacer investigación. Es una tarea al modo de la que Vigotsky (1988) denominó "la zona de desarrollo próximo", es decir una serie de procesos de maduración que tienden al desarrollo de funciones superiores que se alcanzan con la guía de alguien más capacitado o de un par cooperante, todo en función de lograr aprendizajes superiores.
Lamentablemente, el vínculo entre investigador enseñante y estudiante investigador suele verse obstaculizado por la percepción ciertamente común de que la investigación formativa es una actividad riesgosa, en tanto puede no ofrecer un mayor beneficio para los profesores, si ello se analiza desde la consideración de que existe un mayor estímulo económico a la investigación, alejada de los procesos de enseñanza, y un menor estímulo al reconocimiento de las horas de trabajo dedicadas a la docencia (Fiarweather, 2005, citado por Jalbert, 2008).

Por tal razón, el estímulo a la investigación de los estudiantes se propone como una forma de lograr el equilibrio entre las cargas docentes y las exigencias de producción investigativa que recaen en los profesores de las facultades de Contaduría Pública; más aún en el contexto de las demandas de acreditación. Para tal efecto, se sugiere la producción investigativa de los estudiantes como una manera de equilibrar las exigencias de enseñanza con las de producción investigativa. Desde esta propuesta, la investigación es vista como una didáctica de enseñanza de las áreas a la par que una forma de producir nuevo conocimiento.

En conclusión, "una cuidadosa atención a lo que enseñamos, cómo enseñamos y cómo podemos acomodar y facilitar el aprendizaje de los estudiantes es un esfuerzo digno de reconocimiento. El éxito de ese esfuerzo debe ser reconocido, recompensado y valorado mediante publicaciones, de forma que otorgue igualdad de consideración con otras ramas de la erudición y la investigación contable" (St. Pierre et al., 2009, 130).

\subsubsection{Discusión sobre la ausencia de la crítica}

Como ya se ha dejado dicho en apartados anteriores, la crítica tiene un papel protagónico en la formación para la investigación, especialmente como propósito de formación; no obstante, en una lectura con el lente de la didáctica crítico constructiva, la crítica pareciera esfumarse. 
En un primer lugar, no pareciera haber crítica en las temáticas, una vez que en términos generales se abordan temáticas cuya construcción ha obedecido más a pretensiones funcionalistas, y también se abordan sin una perspectiva crítica. Como ya se anotó, las temáticas más recurrentes en el interés del estudiante corresponde con las modas de la dinámica organizacional o académica de la contabilidad. De acuerdo con Klafki (1986), temáticas que en esencia pueden ser instrumentales, son susceptibles de abordarse desde perspectivas o con metódicas críticas; de modo que temáticas como las tendencias mundializadoras de la contabilidad, la valoración monetaria de recursos intangibles y naturales, el control de la riqueza y la propiedad privada, entre otras, deben ser sometidas a la crítica mediante la decantación de sus lógicas subyacentes y su utilización como pretextos para discutir ética, moral y políticamente el mundo, no con la intención de hacer propaganda a una perspectiva concreta, sino de mostrar los horizontes para que el estudiante construya sus propias opciones.

Sin embargo, hay una tendencia a asociar la crítica con la capacidad de discutir teóricamente la contabilidad. En publicaciones internacionales, se encuentra que muchas de las intervenciones se orientan al fortalecimiento de un pensamiento crítico, entendido como un pensamiento profundo en el cual las críticas a ciertos textos y las respuestas a interrogantes que obliguen a establecer relaciones significativas y profundas entre hechos, son la base para valorar el nivel de crítico (English et al., 2004, citado por Lloyd, 2007; Cullen et al., 2004; St. Pierre et al., 2009). Para Baeas (1999, citado por Valenzuela, 2008) el pensamiento profundo, implica tener una base de sustentación de sus propias creencias utilizando para ello el razonamiento, la resolución de problemas y la toma de decisiones.

Para Lloyd (2007) este pensamiento profundo se evalúa desde su experiencia didáctica, como el resultado de alcanzar los siguientes objetivos de aprendizaje: fortalecer en los estudiantes la capacidad para abordar la lectura de diversas y ricas fuentes de información que pueden utilizar en sus carreras, con la consecuente ganancia en el conocimiento del área; pensar críticamente acerca de las fortalezas y debilidades de un artículo; aprender directamente de una auditoría profesional que tiene conocimientos valiosos tanto en el tema específico en el cual los estudiantes están interesados, como en el ejercicio de la profesión.

Asuntos estos que, por supuesto, resultan valiosos para la dimensión profesional del sujeto estudiante, pero que probablemente deja escapar la mirada crítica sobre el mismo contexto organizacional y aún más el social amplio.

Frente a esta despolitización de lo crítico, cabe acudir a Giroux $(1990,177)$ quien postula que la misión del profesor como intelectual, la cual se orienta hacia la formación política, gira en torno a dos aspectos: hacer la pedagogía más política, lo que significa "ayudar a los estudiantes a desarrollar una fe profunda y duradera en la lucha para superar las injusticias económicas, políticas y sociales, para humanizarse más a fondo ellos mismos como parte de esa lucha"; el otro aspecto es el de hacer más política, lo cual significa "servirse de formas de pedagogía que traten a los estudiantes como sujetos críticos, hacer problemático el conocimiento, recurrir al diálogo crítico y afirmativo, y apoyar la lucha por un mundo cualitativamente mejor para todas las personas".

En el caso concreto de la formación contable, McPhail (2005) afirma que la inclusión de la ética dentro de los planes de estudio cae en el lugar común de los registros de casos aislados de corrupción en ausencia de una inserción en el contexto de la economía política; de hecho la formación en economía política no es un requisito obligatorio para la titulación.

Así, la formación técnica en detrimento de los conocimientos críticos y ético emocionales, sumada a las presiones de la comercialización de la practica contable "han dado lugar a una de-profesionalización de la contabilidad y un cambio hacia una mayor orientación emprendedora" (Willmott \& Sikka, 1997, citado por McPhail, 2005, 214). Este fenómeno se ha dado en los Estados Unidos por el cambio de la vocación universitaria que pasó de formar ministros y líderes cívicos en una economía agraria, a formar especialistas y directivos de una sociedad industrial y de servicios, lo cual ha conducido a la formación en 
la competencia y la efectividad, germen de la formación individualista a expensas de la conciencia social y los valores comunitarios (Reid, 1980; Schwartz et al., 1991; citados por McPhail, 2005, 215).

Por tal razón, McPhail $(2005,218)$ propone una experiencia didáctica orientada bajo el estudio de caso, la cual se aplica en el contexto de Ruchill, un barrio deprimido de Glasgow. Se elige esta zona porque a pesar de ser tradicionalmente privada de muchas condiciones sociales, hay en ella un conjunto de cooperativas y de acciones comunales que ofrecen una oportunidad para discutir el negocio, los factores económicos y contables, que pueden haber contribuido hacia la pobreza, la violencia y la drogadicción en el sector; sin embargo, también proporciona ideas interesantes sobre cómo las empresas y la contabilidad están involucrados en diferentes formas, en la regeneración de la zona.

El trabajo pretende enfrentar la tendencia a concebir al contador como un experto profesional en lugar de un "actor de lo público". El proyecto apunta a la implementación de prácticas comunitarias probono en el mismo sentido que las que desarrollan los abogados y los médicos, trascendiendo la expresión de ética egocéntrica basada en la afirmación de la valía propia a partir del ejercicio del altruismo, o actitudes contradictorias como en el caso del altruismo de Deloy (citado por McPhail, 2005, 221), que podría evidenciar "una ironía potencial de los contadores que a través de servicios gratuitos, ayuden a hacer frente a problemas de la comunidad a los que pudieron haber contribuido inicialmente en su condición de consultores y auditores a las corporaciones locales".

En última instancia, aquí la crítica apunta a la formación del sentido de lo público, superando la ética individualista que se constituye en la base moral de la sociedad de mercado y que proporciona los valores de las formas convencionales de la contabilidad. Al centrarse en la responsabilidad pública, esto puede empujar el análisis de la contabilidad en dimensiones más allá de los intereses de la empresa o de la profesión, o incluso de la persona del contador. Una discusión adecuada de estas cuestiones, requerirá un análisis más explícito de los valores y la ideología que en la actualidad definen las relaciones y estructura de rendición de cuentas.

De allí que sea necesario reconstituir el sentido de las competencias sociales, llevándolo más allá de la capacidad para trabajar en equipo, que encarna una reducción de lo social, para emprender el compromiso de desarrollar habilidades cívicas que, en términos de Boyte \& Farr (1997, citados por McPhail, 2005, 223). incluyen "tolerancia a las visiones políticas, religiosas y raciales, sentido de agencia en el cumplimiento de las tareas gubernamentales-político, liderazgo y participación en esas instancias, el pensamiento crítico, la deliberación pública y un sentido de obligación cívica y compromiso para tomar acciones colectivas".

Esto significa que es necesario continuar reivindicando el potencial emancipador de la investigación, pero que esta intención debe acompañarse de la convicción profunda del poder que tiene la investigación contable para contribuir a la transformación de las condiciones de inequidad social, pero así mismo implica revisar los arreglos metódicos que se establecen como medios para alcanzar esa transformación. En ese sentido, la elección por el estudio de caso parte del reconocimiento de la importancia del espacio en los procesos social y cultural (McPhail, 2003; Harvey, 1996; Miller \& O'Leary, 1994; citados por McPhail, 2005). La relación entre la Contabilidad y el interés público, se basa en la afirmación de que el lugar donde tiene lugar la educación es tan importante como su contenido (McPhail, 2002; McPhail, 2003; citados por McPhail, 2005, 217).

Con respecto al proceso de escritura, se observa la reivindicación de esta como un proceso de inserción en la cultura académica que faculte al estudiante para acceder a las dinámicas discursivas de las disciplinas. En este caso, la labor del maestro, de acuerdo con Perelman \& Olbrechts Tyteca (citados por Ruiz, $2011,396)$, consiste en iniciar en las reglas de la disciplina, las técnicas y las nociones, así como las formas de "criticar sus resultados en función de las exigencias de la propia disciplina".

Debido a esta codificación del discurso, se agencian restricciones que alejan al sujeto de su relación con 
el mundo, de sus formas particulares de valorarlo y de sus relaciones con lo preferible. Como lo indica Foucault (citado por Ruiz, 2011, 396): "se puede decir la verdad siempre que se diga en el espacio de una exterioridad salvaje; pero no se está en la verdad más que obedeciendo a las reglas de una 'policía' discursiva que se debe reactivar en cada uno de sus discursos", lo cual somete al sujeto a las condiciones de la disciplina.

Al respecto, se reivindica el valor del ensayo como una forma de escritura que con base en la producción del conocimiento, acude a la naturalidad del lenguaje y al potencial argumentativo de la poesía, como una forma de liberar la expresión de las imposiciones y controles propios de las comunidades académicas y científicas (Adorno, 1962; Vélez, 2000; Larrosa, 2003; citados por Ruiz, 2011). Es posible hacerlo, pues como bien lo indican los profesores, el propósito de la investigación formativa no es producir investigación en el sentido estricto, sino facultar al estudiante para que se haga consciente de la constitución de su subjetividad en su relación con su pensamiento, su contexto y el conocimiento.

Finalmente, el desarrollo de la argumentación, no resuelve en sí mismo el problema de la formación crítica. En general, existen diversas teorías de la argumentación, las cuales justifican los criterios de verdad desde concepciones diferentes, y en ocasiones antagónicas, del sujeto y del lenguaje. Algunas centran su énfasis en los argumentos (teorías lógicas), otras en la discusión (teorías dialécticas) y otras en la persuasión (teorías retóricas). Cada una con sus propias potencialidades tanto metódicas como formativas. Algunas estimulan las competencias y el debate, otras enfatizan la unilateralidad de la razón, otras caen en distorsiones estilísticas y algunas como las concepciones dialógicas, entienden el lenguaje como la posibilidad de la acción intersubjetiva transformadora.

\section{Comentarios de cierre: vindicación de la formación investigativa en contabilidad}

Si bien las manifestaciones de los actores consultados acerca de la formación investigativa contable parecieran evidenciar una situación desalentadora, es necesario vindicar el ejercicio realizado en tanto pone en presencia los sentires ocultos de los profesores en torno a sus prácticas de enseñanza y deja abiertas algunas rutas para futuros abordajes de la problemática. En esa vía, los hallazgos, que a simple vista pudiesen parecer meramente anecdóticos, revelan importantes perspectivas de sentido que, por las limitaciones de formato de este artículo, no logran develarse en toda su dimensión dialógica.

La didáctica crítico-constructiva klafkiana constituye una perspectiva teórico-metodológica que ensancha el horizonte de interpretación de la realidad del ejercicio docente, de forma que sin abandonar la preocupación por los propósitos y las intencionalidades de la formación de los contables, permite recuperar para el debate académico, las prácticas metódicas de los profesores, como elemento de capital importancia para la construcción de mejores relaciones académicas y socio-afectivas entre profesores y estudiantes en la cotidianidad del proceso formativo contable.

Resulta abiertamente paradójico que la formación de los contadores se juzgue en función de lo que las empresas juzgan como útil y pertinente para sí, mientras que en los propósitos de formación, las instituciones de educación superior le asignan a la investigación unos objetivos de claro enfoque socio-humanístico, en correspondencia con las necesidades la sociedad. La diferencia -si acaso no la contradicción- en este aspecto, explica de alguna manera la baja valoración social de la investigación contable en el contexto de aplicación de este estudio.

Habida cuenta de los cuestionamientos a la utilidad de los productos investigativos de los estudiantes y la preeminencia de los objetivos socio-humanísticos en la formación investigativa, habrá que poner en consideración si es más pertinente ajustar la rigurosidad en la formulación de proyectos de investigación aplicada, o por el contrario, fortalecer la dinámica reflexiva de otro tipo de productos cuyo proceso escritural fortalezca lo técnico tanto como la movilización del pensamiento, y que así representen una respuesta más adecuada a esos propósitos formativos.

Sin perjuicio de la evidente importancia de la investigación contable y de la subsecuente relevancia que 
se le asigna a la formación investigativa en este campo de conocimiento, las instituciones de educación superior están abocadas a reflexionar en torno a la forma como se diseñan y operan sus contenidos, en diálogo con los propósitos de formación de las instituciones -frecuentemente mediados por consideraciones políticas, culturales e incluso religiosas- y con las necesidades del conjunto de la sociedad, cada vez más colonizadas por la lógica empresarial, a la cual pareciera reducirse la idea de sociedad civil.

Más allá de los hallazgos y aprendizajes heredados de este estudio, subsiste la preocupación de los autores por adentrarse en el análisis de los sentidos construidos en cada escenario de formación, en el impacto que estas prácticas han representado para los profesores y los estudiantes, y en las posibilidades de transformación intersubjetiva que pudiesen estar ocultas en todo lo cotidiano del proceso de formación investigativa contable. Por ello, este documento deja claro que la intención de la formación investigativa no es siquiera formar investigadores contables -lo cual también es deseable- sino abrir puertas a la comprensión de los fenómenos contables desde la investigación, en beneficio de un ejercicio profesional más consciente, más ético, y ojalá más comprometido.

Otro aspecto relevante a modo de invitación derivada de este estudio y presente también en publicaciones nacionales e internacionales, tiene que ver con la integración entre el mundo profesional y el mundo de la investigación contable. Valdría la pena que en Colombia, y en otros contextos, la investigación contable sea concebida como una práctica profesional en sí misma, ya que ella puede contribuir a aportar soluciones a los campos específicos de la profesión; para lo cual es necesario que los artículos de investigación amplíen su campo de acción a un público mucho más amplio que el de los investigadores, de modo que se favorezca el diálogo entre la comunidad académica y la comunidad profesional de las organizaciones, relación que estaría mediada por dos instancias: de un lado, una apuesta porque las técnicas de la investigación sean útiles también para resolver problemas organizacionales a los que se enfrentarán los futuros profesionales; y del otro lado, el hecho de que los profesionales contables deben comprender asuntos generales de la investiga- ción, pues ellos también pueden formar parte de los comités consultivos que deciden la financiación de la investigación, y así tendrían mayores elementos de juicio (Wesley et al., 1970).

Esto demandaría diversas acciones:

- Crear habilidades en los estudiantes para que aprendan a valorar textos científicos, tanto desde el punto de vista del método científico, como desde el punto de vista crítico discursivo, y de las capacidades argumentativas (Lloyd, 2007).

- Establecer una comparación entre las reflexiones que surgen en el contexto de los artículos de investigación y la práctica real de los profesionales, mediante entrevistas que favorezcan y realicen contrastaciones (Lloyd, 2007).

- Siguiendo a Cullen et al. (2004), acudir a estudios de caso "sucios", es decir que involucren variables complejas y situaciones sociales concretas en las cuales se involucren valores, con el fin de afrontar las soluciones a partir de nuevas interpretaciones que permitan fortalecer en el estudiante el aspecto comunicativo e intersubjetivo y de esta forma devolverle a la contabilidad su potencial comunicativo menguado debido a los énfasis tecnicistas.

\section{Referencias}

Alvarado, S. \& Ospina, H. (2009). La investigación cualitativa: una perspectiva desde la reconstrucción hermenéutica. En: Tonón, G. (comp.) Reflexiones Latinoamericanas sobre Investigación Cualitativa. Buenos Aires: Prometeo y Universidad Nacional de La Matanza.

Apostolou, B., Hassell, J., Rebele, J. \& Watson, S. (2010). Accounting education literature review (2006-2009). En: Journal of Accounting Education, 28: 145-197

Apostolou, B., Dorminey, J., Hassell, J. \& Watson, S. (2013). Accounting education literature review (2010-2012). En: Journal of Accounting Education, 31: 107-161.

Archel, P. (2007). Teoría e investigación crítica en contabilidad. Un estudio de Caso. Madrid: AECA.

Arendt, H. (1993). La condición humana. Barcelona. Ed. Paidós.

Ballantine, J. \& McCourt, P. (2004). A critical analysis of students' perceptions of the usefulness of the case study method in an advanced management accounting module: the impact of relevant work experience. En: Accounting Education, 13 (2): 171-189.

Bauman, Z. (2009). Comunidad. En busca de seguridad en un mundo hostil. Madrid: Siglo XXI: 85-106. 
Beck, U. (2008). ¿Qué es la globalización? Falacias del globalismo, respuestas a la globalización. Barcelona: Paidós.

Bonilla-Castro, E. \& Rodríguez, P. (1997). Más allá del dilema de los métodos.

Bruchstein, J. (2010). Una pedagogía de la emancipación: entrevista con Peter McLaren. Descargado el 20 de noviembre de: http://www. pagina12.com.ar/diario/universidad/10-148473-2010-06-29. html

Cardona, J. \& Zapata, M. (2006). Educación contable. Antecedentes, actualidad y prospectiva. Medellín: Universidad de Antioquia.

Carlino, P. (2004a). La escritura académica, cuatro dificultades de la enseñanza universitaria. En: Educere, 8(26): 321-327. Descargado el 20 de mayo de 2011 de: http://23118.psi.uba. ar/academica/cursos actualizacion/recursos/carlino cuatro.pdf.

Carlino, P. (2004b). ¿Quién debe ocuparse de enseñar a leer y a escribir en la universidad? En: Lectura y Vida, 25(1): 6-14.

Carlino, P. (2005). La escritura en investigación. En: Seminario de Investigación Permanente, Cátedra de Maestría, Universidad de San Martín: Argentina. Descargado el 3 de septiembre de 2013 de: http://www.udesa.edu.ar/files/ESCEDU/DT/DT19. CARLINO.PDF.

Cortés, J. (2009). Investigación y pensamiento crítico. En: Memorias I Encuentro Nacional de Profesores de Contaduría Pública. Bogotá: Pontificia Universidad Javeriana: 565-584

Cortina, A. (1986). Ética mínima. Introducción a la filosofía práctica. Madrid: Tecnos.

Cullen, J., Richardson, S. \& O`Brien, R. (2004). Exploring the teaching potential of empirically-based case studies. En: Accounting Education, 13(2): 251-266.

De Zubiría, S. (2006). Hacia una pedagogía dialogante. Bogotá: Editorial Magisterio.

Evans, J., Feng, M., Hoffman, V., Mosser, D. \& Van der Stede, W. (2014). Points to consider when self-assessing your empirical accounting research. SSRN, 5. Disponible en: http://ssrn.com/ abstract $=2120181$

Flórez, R. (1994). Hacia una pedagogía del conocimiento. Santafé de Bogotá: McGraw Hill.

Galeano, E. (2004). Diseño de proyectos de investigación cualitativa. Medellín: Universidad Eafit.

García, M. (2012). Lenguaje pedagógico, filosofía e investigación: Relación con la construcción de pensamiento y cultura académica en contabilidad. En: Revista Lúmina, 13: 152-166.

Giraldo, G. (2009). La formación del estudiante de Contaduría Pública: la pertinencia de la actitud crítica e interpretativa. En: Memorias I Encuentro Nacional de Profesores de Contaduría Pública. Bogotá: Pontificia Universidad Javeriana: 585-596.

Giroux, H. (1990). Los profesores como intelectuales. Barcelona: Paidós.

Gómez, M. (2010). Dinámica de la concepción y la enseñanza de la teoría contable en Colombia (1970-2000): una exploración institucional. En: Barrios, C. \& Rojas, W. (eds.) Conjunciones y disertaciones: pensando la contabilidad en el siglo XXI. Cali: Universidad del Valle - Pontificia Universidad Javeriana: 127-159.

Gracia, E. (2002). Estado actual de la educación contable en Colombia. En: Quijano, O., Gracia, E., Martínez, G., Ariza, E. \& Rojas, W. (eds.) Del hacer al saber. Realidades y perspectivas de la educación contable en Colombia. Popayán: Universidad del Cauca: 85-111.

Gray, R. (2002). The social accounting project and accounting, organizations and society: privileging engagement, imaginings, new accounting and pragmatism over critique? En: Accounting, Organizations and Society, 27 (7): 687-708.

Harnecker, M. (2013). Un mundo a construir (nuevos caminos). Barcelona: El Viejo Topo.

Herrera, J. (2010). La comprensión de lo social. Horizonte hermenéutico de las ciencias sociales. Bogotá: Cinde.

IAESB (2014). International education standars. Handbook of International Education Pronouncements. London: IFAC: 32-96.

IFAC (2008). Manual de los Pronunciamientos Internacionales de Formación. Nueva York: IFAC

Jalbert, T. (2008). Experiences in publishing peer-reviewed research with undergraduate accounting and $\square$ nance students. En: Journal of accounting education, 26: 104-117.

Klafki, W. (1986). Fundamentos de la didáctica crítico constructiva. En: Revista de Educación, 280: 37-79.

Klafki, W. (1988). ¿Se modifica la realidad escolar por efecto de la investigación escolar? En: Revista de Educación, 286: 97-113.

Larrinaga, C. (1999). Perspectivas alternativas de investigación en contabilidad: una revisión. En: Revista de Contabilidad, 2: 103-131.

Larrinaga, C. \& Moneva, J. (2005). Responsabilidad social e información de sostenibilidad. En: XIII Congreso Internacional de AECA, Oviedo: AECA: 4-17.

Lechner, N. (2002). Las sombras del mañana. Obras escogidas. Santiago de Chile. LOM Ediciones.

León, F. (2009). La educación contable en el contexto anglosajón: una mirada a los años de construcción de comunidad. En: Cuadernos de Contabilidad, 10(27): 219-245.

Lloyd, J. (2007). Using student-centered writing assignments to introduce students to accounting research and facilitate interaction with accounting practitioners. En: Global Perspectives on Accounting Education, 4: 61-68.

Loaiza, F. \& Rueda, G. (2011). Importancia de la fundamentación teórica para los procesos de formación en investigación contable. En: Memorias II Encuentro Nacional de Profesores de Contaduría Pública. Bogotá: Universidad Nacional de Colombia.

McLaren, P. (2005). La vida en las escuelas. México y Buenos Aires: Siglo XXI editores.

McPhail, K. (2005). Care in the community: professional ethics and the paradox of pro bono. En: Accounting Education: an International Journal, 14(2): 213-227.

Martínez, G. (2006). Los desafíos de la educación contable: encrucijada de una formación monodisciplinaria en un entorno complejo e incierto. En: Revista Porik An, 8(11): 13-72.

Martínez, J. (2010). La universidad productora de productores: entre biopolítica y subjetividad. Bogotá: Universidad de la Salle.

Max Neef, M. (2013). Apología de otro mundo posible. En: Testimonio Latinoamericano. Senda y rastro de la Contabilidad en una región del tiempo. Medellín: Politécnico Colombiano: 57-66.

Morin, E. (1999). Los siete saberes necesarios para la educación del futuro. París: Unesco-Santillana.

Morse, J. (ed.) (2006). Asuntos críticos en los métodos de investigación cualitativa. Medellín: Universidad de Antioquia. (1st edition 1994, Sage Publications Inc.)

Muñoz, S. \& Sarmiento, H. (2010). La formación del sujeto político en la educación contable: un reto para la universidad y una provocación para el pensamiento. En: Revista Teuken Bidikay, 1: $165-183$.

Naïr, S. (2003). El Imperio frente a la diversidad del mundo. Barcelona: Areté 
Ospina, C. (2005). Sobre la investigación en contabilidad: algunos apuntes. En: Revista Contaduría, 46: 73-110.

Patten, D. (2013). Lessons from the third wave: a reflection on the rediscovery of Corporate Social Responsibility by the mainstream accounting research community. En: Financial Reporting, 2: 9-26.

Pesqueux, I. (2009). Los problemas actuales de la investigación en contabilidad y control. El problema de la norma. En: Perspectivas críticas de la contabilidad contemporánea: 19-41. Cali: Universidad del Valle.

Quijano, O. (2004). Estandarización de la educación contable: el proyecto escolar de los gremios económicos. En: La Contaduría Pública en el nuevo entorno global. Popayán: Universidad del Cauca.

Rojas, W. (2009). Congoja por una educación contable fútil. En: Irrupciones significativas para pensar la contabilidad: 193-207. Cali: Universidad del Valle.

Rueda, G. \& Pinzón, J. (2009). Retos y transformaciones en la investigación formativa contable. Una reflexión en la reciente experiencia en la Pontificia Universidad Javeriana. En: Memorias I Encuentro Nacional de Profesores de Contaduría Pública. Bogotá: Pontificia Universidad Javeriana: 547-563.

Ruiz, G. (2011). El ensayo y la alfabetización académica: limitaciones y posibilidades didácticas. En: Revista Perspectivas Educativas, 4: 387-409.

Runge, A. (2008). Ensayos sobre pedagogía alemana. Bogotá: Universidad Pedagógica Nacional.

Runge, A. (2011). Conceptos básicos de pedagogía. Obtenido del website didáctica y pedagogía: https://sites.google.com/site/ pedagogiaydidacticag13/home/presentaciones.

Runge, A. \& Garcés, J. (2011). Educabilidad, formación y antropología pedagógica: repensar la educabilidad a la luz de la tradición pedagógica alemana. En: Revista Guillermo de Okcham, 9(2): 13-25.
Sarmiento, H. \& Muñoz, S. (2011). Banderas en alto: una arqueología del proceso de nacionalización de la Contaduría Pública en Colombia. Medellín: Politécnico Colombiano Jaime Isaza Cadavid.

St. Pierre, K., Wilson, R., Ravenscroft, S. \& Rebele, J. (2009). The role of accounting education research in our discipline. An editorial. En: Issues in Accounting Education, 24(2): 123-130.

Stiglitz, J. (2002). El malestar en la globalización. Madrid: Taurus.

Tamayo, O. (2003). Caracterización general de la didáctica de las ciencias. Trabajo no publicado, documento del programa de Maestría en Educación y Desarrollo Humano. Manizales: Cinde/ Universidad de Manizales.

Tamayo, O., Vasco, C., Suárez, M., Quiceno, C., García, L. \& Giraldo, A. (2010). La clase multimodal. Formación evolución de conceptos científicos a través de tecnologías de la información y la comunicación. Manizales: Universidad Autónoma de Manizales.

Valenzuela, J. (2008). Habilidades de pensamiento y aprendizaje profundo. En: Revista Iberoamericana de Educación, 46(7): 2-9.

Vargas, G. (2011). La formación como eje de las relaciones entre pedagogía y administración. En: Revista Electrónica Forum Doctoral, 3: 126-145. Disponible en: http://www.eafit.edu.co/ revistas/forum-doctoral/Documents/ed3/Revista_forum_Doctoral Edici\%C3\%B3n especial N.3 .pdf

Vigotsky, L. (1988). El desarrollo de los procesos psicológicos superiores. México: Editorial Crítica - Grupo editorial Grijalbo.

Watson, S., Apostolou, B., Hassell, J. \&. Webber, S. (2007). Accounting education literature review (2003-2005). En: Journal of Accounting Education, 25: 1-58.

Wesley, J., Neumann, F. \& Revsine, L. (1970). A research methodology course for accountants. En: The Accounting Review, 45 (4): 789-795.

Zemelman, H. (2001). Pensar teórico y pensar epistémico: los retos de las ciencias sociales latinoamericanas. En línea: http:// www.ipecal.edu.mx/Biblioteca/Documentos/Documento7.pdf. Consultado el 29.11.13 